\title{
El comercio de un monopolista. Volumen, contenido y sentido de la circulación, según un estudio de caso (Río de la Plata, 1770-1820)*
}

\author{
The Trade of a Monopolist. Volume, Content \\ and Direction of Traffic, According to a Case Study \\ (Río de la Plata, 1770-1820)
}

\section{Mariano Martín Schlez \\ Universidad Nacional del Sur CONICET}

El trabajo analiza la circulación dinamizada durante el período colonial tardío por el comerciante mayorista español, radicado en Buenos Aires, Diego de Agüero. Mediante la triangulación de diversos tipos de fuentes públicas y privadas, se mide el volumen del giro mercantil, se describe y pondera su contenido y se dilucida el sentido del flujo de riquezas.

Palabras Clave: Imperio español; Río de la Plata; Siglo XVIII; Comercio colonial; Capital mercantil.

The paper analyzes the trade during the late colonial period, made by the Spanish merchant based in Buenos Aires, Diego de Agüero. By triangulation of public and private sources, the article describes the content of the commerce and elucidates the meaning that had the flow of wealth, summarizing the key features of Agüero's trade.

KeYwords: Spanish Empire; River Plate; XVIII Century; Colonial Trade; Merchant Capital.

* Este trabajo ha sido financiado por dos becas doctorales del Consejo Nacional de Investigaciones Científicas y Técnicas de la Argentina (CONICET, Becas PG TI 07 y PG TII 11) y el autor ha realizado una estancia de investigación en Sevilla gracias a una beca científica de la École des Hautes Études Hispaniques et Ibériques, Casa de Velázquez, Madrid. Agradezco los comentarios y aportes de los doctores Fernando Enrique Barba, Emilio Fabián Harari y Hernán Asdrúbal Silva. 


\section{Metodología, fuentes y objetivos}

La historiografía americanista ha llevado adelante un programa de investigación que nos permite hoy, más allá de una serie de debates puntuales, contar con una detallada aproximación al comercio atlántico en tiempos del Imperio español. ${ }^{1}$ Dicho desarrollo ha dado cuenta de los aspectos cuantitativos del tráfico, ${ }^{2}$ así como del aspecto cualitativo determinante: el carácter exclusivista del comercio colonial español y su debilidad relativa. ${ }^{3}$

Dicha evolución planteó la necesidad de avanzar en nuestra comprensión de los protagonistas centrales del tráfico, los grandes comerciantes atlánticos, para resolver los problemas que las aproximaciones generales y seriales no pudieron llevar a buen término, vinculados no solo al contenido, volumen y movimiento de la circulación, sino también al carácter social de la Carrera de Indias. ${ }^{4}$ En este sentido, existió un acuerdo en la pertinencia de dinamizar estudios de caso que sistematicen la documentación privada (correspondencia, testamentarias, documentación contable), a la luz de las fuentes tradicionalmente utilizadas (registros de navíos, protocolos notariales), aunque señalándose las dificultades de una aproximación de estas características, vinculadas a la escasez de archivos privados y al enorme trabajo que requiere el tratamiento de las voluminosas fuentes públicas y seriales. ${ }^{5}$

Desde entonces se profundizaron, retomando los estudios clásicos sobre el tema, ${ }^{6}$ los trabajos dedicados a los grandes comerciantes, los que atendieron a la diversidad geográfica y temporal que caracterizó al Imperio español ${ }^{7}$ y a la modernidad atlántica, ${ }^{8}$ observándose el predominio de análisis de redes, ${ }^{9}$ así como la actuación política y corporativa de los cargadores. ${ }^{10}$

1 Haring, 1939; Chaunu y Chaunu, 1955-59; Vilar, 1962; García Fuentes, 1980; Fontana, 1982; García-Baquero, 1996; Martínez Shaw, 1981; Fontana y Bernal, 1987; Bernal, 1992; Fisher, 1993; Silva, 1993.

2 Mediante la apelación a diferentes tipos de documentación, como registros de navíos, protocolos notariales, archivos privados y publicaciones periódicas (como las Gacetas holandesas y el Diario Marítimo de la Vigía, de Cádiz). Véase Morineau, 1985; Alfonso Mola, 2013.

3 Laviana Cuetos, 2006; Silva, 2013.

4 García-Baquero, 1992, 271.

5 Bernal, 1992, 349-353.

6 Vilar, 1962; Brading, 1975; AAVV, 1976; Martínez Shaw, 1981; Vila Vilar, 1985; Heredia Herrera, 1989; García-Baquero, 1989, 1991.

7 Molas Ribalta, 1985; Torres Sánchez, 2000; Bustos Rodríguez, 2005; Jumar, 2011.

8 Crespo Solana, 2010.

9 Dalla-Corte, 2000; Fernández Pérez, 1997; Moutoukias, 1992.

10 Galmarini, 1986; García de Flöel, 2000; Supervielle, 2004; Böttcher, 2008; Poensgen, 1998. 
Naturalmente, también han sido recurrentes los estudios que privilegiaron los aspectos económicos y sociales que caracterizaron a los negociantes de Indias, los que dieron cuenta de la amplia gama de actividades económicas desplegadas a ambos lados del océano, que incluían producción textill, ${ }^{11}$ empresas navieras, ${ }^{12}$ minería, ${ }^{13}$ propiedades inmobiliarias, ${ }^{14}$ viñas, ${ }^{15}$ haciendas ${ }^{16}$ y finanzas. ${ }^{17}$

Aunque este notable avance empírico permite un análisis más detallado de las características de los comerciantes modernos, aún existen debates en torno a su conceptualización: clase, grupo, fracción, estamento y élite son algunas de las diversas formas en que son caracterizados. ${ }^{18}$

Para avanzar en la dilucidación de este problema consideramos necesario que los estudios de caso analicen una serie de variables que permitan su comparación a escala universal, ${ }^{19}$ particularmente la especialización geográfica, el contenido y el volumen del giro mercantil. En este sentido, se vuelve pertinente describir los mercados unidos por el tráfico, con el objetivo de evaluar la flexibilidad que tuvieron las rutas de comercio, sobre todo a la hora de vincularse con mercados extranjeros en tiempos de crisis. ${ }^{20}$

Por su parte, una mirada más atenta de la circulación nos obliga a mejorar nuestra ponderación de la estructura de mercancías traficadas entre la Península y América, ${ }^{21}$ tanto en lo que respecta a la proporción entre productos españoles y extranjeros exportados a través del Atlántico, así como en la cuantificación de los volúmenes globales traficados y el peso que cada mercancía tuvo en el comercio colonial. ${ }^{22}$ Un mejor conocimiento del contenido concreto de las mercancías traficadas por las compañías modernas nos permitirá conocer su grado de especialización y evaluar la hipótesis de

11 Martínez Shaw, 1981.

12 Herrero, 2013.

13 Lohmann Villena, 1994.

14 Aguado de los Reyes, 2013.

15 Aillón Soria, 2009.

16 Bernal y García-Baquero, 1976; Gelman, 1996.

17 Bernal, 1992.

18 Brenner, 2011; Büschges y Langue, 2005; Socolow, 1991.

19 Crespo Solana, 2010, 21.

20 Malamud, 1985.

21 García-Baquero, 1992, 197-198.

22 Aunque se ha probado que el problema central del comercio español provenía de su carácter comisionista, en tanto el grueso de las mercancías exportadas eran extranjeras, aún no existen acuerdos en torno al porcentaje representado por la industria española: mientras que García-Baquero considera que apenas alcanzaba el $15 \%$, el estudio de John Fisher para el período posterior a 1778 concluye que el valor de las mercancías peninsulares alcanzó el $51 \%$ del total exportado. Véase al respecto García-Baquero, 1992, 211; y Fisher, 1985, 46. 
que los comerciantes tienden a multiplicar sus actividades a medida que aumentan el tamaño de negocios. ${ }^{23}$

Finalmente, la cuantificación del volumen del tráfico de cada comerciante individual y la magnitud de riquezas que le permitió apropiarse dicho tráfico es un elemento a tener en cuenta, no solo a la hora de una aproximación más certera a las capas del capital mercantil, sino también para evaluar su capacidad material para influir social, económica y hasta políticamente en los procesos históricos en los que les tocó intervenir.

La evolución historiográfica delinea una agenda, problemática, teórica y metodológica, que se vuelve imprescindible tener en cuenta para avanzar en el conocimiento del comercio colonial. En ese sentido, nuestro trabajo busca realizar un aporte a través del estudio del caso de uno de los más prestigiosos comerciantes mayoristas del Río de la Plata, el español Diego de Agüero. ${ }^{24}$ En este artículo nos dedicaremos, particularmente, a reconstruir el volumen, sentido y contenido de su giro mercantil a lo largo de toda su carrera (1770-1820).

Retomando los aportes metodológicos señalados en el estado del arte, para alcanzar nuestros objetivos hemos apelado tanto a documentación de carácter público como privado, fundamentalmente registros de navíos, protocolos notariales y el archivo privado de la compañía Agüero, que incluye sus copiadores de correspondencia y documentación contable de sus operaciones. Su rastreo implicó la visita a los repositorios de los principales mercados en los que actuó: Archivo General de la Nación (AGN-A) y Museo Histórico Nacional de Buenos Aires (MHN-BA), ambos de Argentina; Archivo General de la Nación (AGN-U) y Museo Histórico Nacional de Montevideo (MHN-M), de Uruguay; Archivo General de Río de Janeiro (AGRdJ), de Brasil; y Archivo General de Indias (AGI), de Sevilla, España.

\section{Volumen y sentido del giro mercantil}

Una aproximación certera al volumen del comercio dinamizado por la compañía Agüero requiere, en primer lugar, sistematizar la información de cada una de las partidas que componen los registros de navíos, junto con los datos ofrecidos por la correspondencia y contabilidad privada (cuentas

23 Braudel, 1984, 327.

24 Dado que presentamos un aspecto parcial de una investigación general, pueden complementarse los temas aquí tratados con la actuación política y corporativa del clan Agüero, en Schlez, 2011, 2012, 2014; y una aproximación al carácter social de sus negocios en Schlez, 2010, 2013a. 
corrientes, cuentas de ventas y gastos, recibos, etc.). Dicha tarea nos ha permitido dilucidar la estructura de las exportaciones legales realizadas desde el Río de la Plata, como resume el gráfico 1.25

La información nos permite analizar aspectos temporales, regionales y cuantitativos de las exportaciones de Agüero. En primer lugar, y aunque no se desprende del gráfico presentado, es pertinente señalar que las exportaciones tienen como destino exclusivo el puerto de Cádiz, por lo que no encontramos vínculos con otros puertos españoles ni extranjeros. ${ }^{26}$ Asimismo, debemos tener en cuenta que el volumen que aquí presentamos implica un piso mínimo, dado que presenta las exportaciones de metales preciosos con exclusión de los frutos del país, debido a que los registros no consignan ni su precio de compra ni su valor de aforo, y su inclusión a través de otra documentación no permitiría realizar una comparación sustentable. No obstante, como veremos en el acápite dedicado al contenido del comercio, veremos que la compra y venta de productos americanos se trató de un aspecto secundario del comercio de Agüero, por lo que no modifica sustantivamente la cuantía presentada.

Pasando entonces a los datos, observamos que la cuantificación de los caudales dirigidos desde el Río de la Plata (Buenos Aires y Montevideo) a Cádiz entre 1770 y 1820 superó el millón de pesos fuertes de América (1.163.633). Es decir que estaríamos frente a uno de los principales comerciantes rioplatenses, hipótesis que debe ser confirmada por estudios de caso que apelen a esta metodología y nos permitan ponderar los resultados. ${ }^{27}$

Por su parte, la sistematización de las exportaciones nos permite realizar algunas apreciaciones en torno al ritmo del tráfico a en la etapa final de la Carrera de Indias. Por un lado, un tímido comienzo, a principios de la década de 1770 , se ve abruptamente detenido a poco de haberse iniciado.

25 Fuentes: AGN-A, Registros de Navíos (salas IX y XIII), Capitanía del puerto (sala III), Registros de Caudales (sala IX), Guías de Aduana (sala X) y Archivo Diego de Agüero (sala IX, legajo 761); AGN-U, Fondo Ex Archivo y Museo Histórico Nacional, Aduana de Montevideo, Registros de Navíos, Fondo Archivo General Administrativo y Particulares (Correspondencia Agüero); AGI, Contratación; Indiferente General; AGRdJ, Fondo Cámara Municipal, Serie Embarcaciones, Termos de entrada no Porto do Río de Janeiro; MHN-M, Archivo Diego de Agüero y Archivo Miguel Fernández de Agüero, Correspondencia, Cuentas Corrientes y Relaciones de Embarque; MHN-BA, Sección libros copiadores del siglo XVIII de Diego de Agüero.

26 Existen montos mínimos dirigidos a sus familiares en Cantabria y otros a sus apoderados en Madrid, pero no dinamizan vínculos comerciales. Las exportaciones a Lisboa en períodos de guerra tienen como destino final Cádiz. Ver Schlez, 2013 b.

27 El trabajo de Jumar (2011), es el único que sistematiza, mediante los registros, el comercio de otro mercader rioplatense, Domingo de Basavilbaso, quien se desempeñó en un período previo al de Agüero. 
MARIANO MARTÍN SCHLEZ

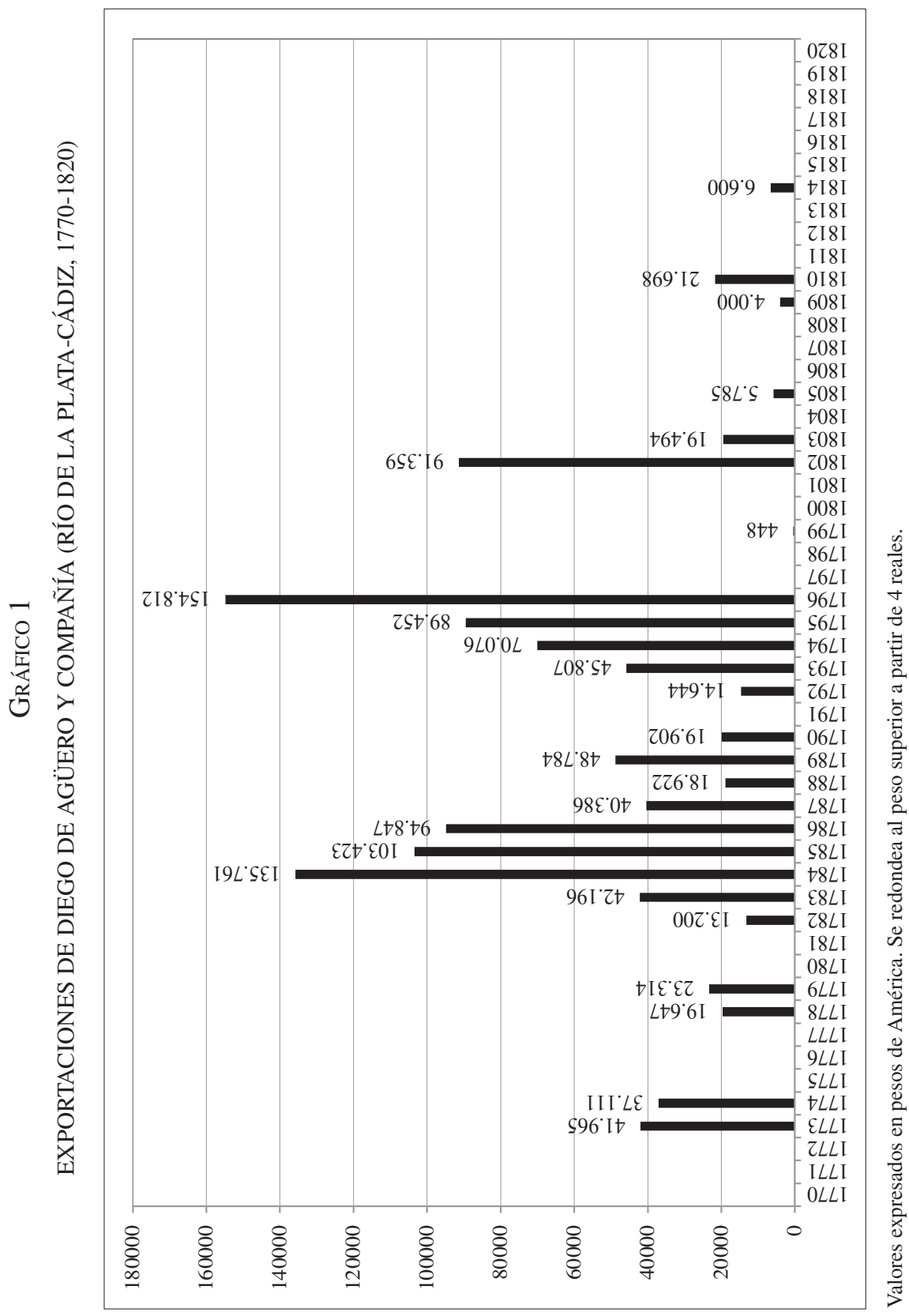




\section{EL COMERCIO DE UN MONOPOLISTA}

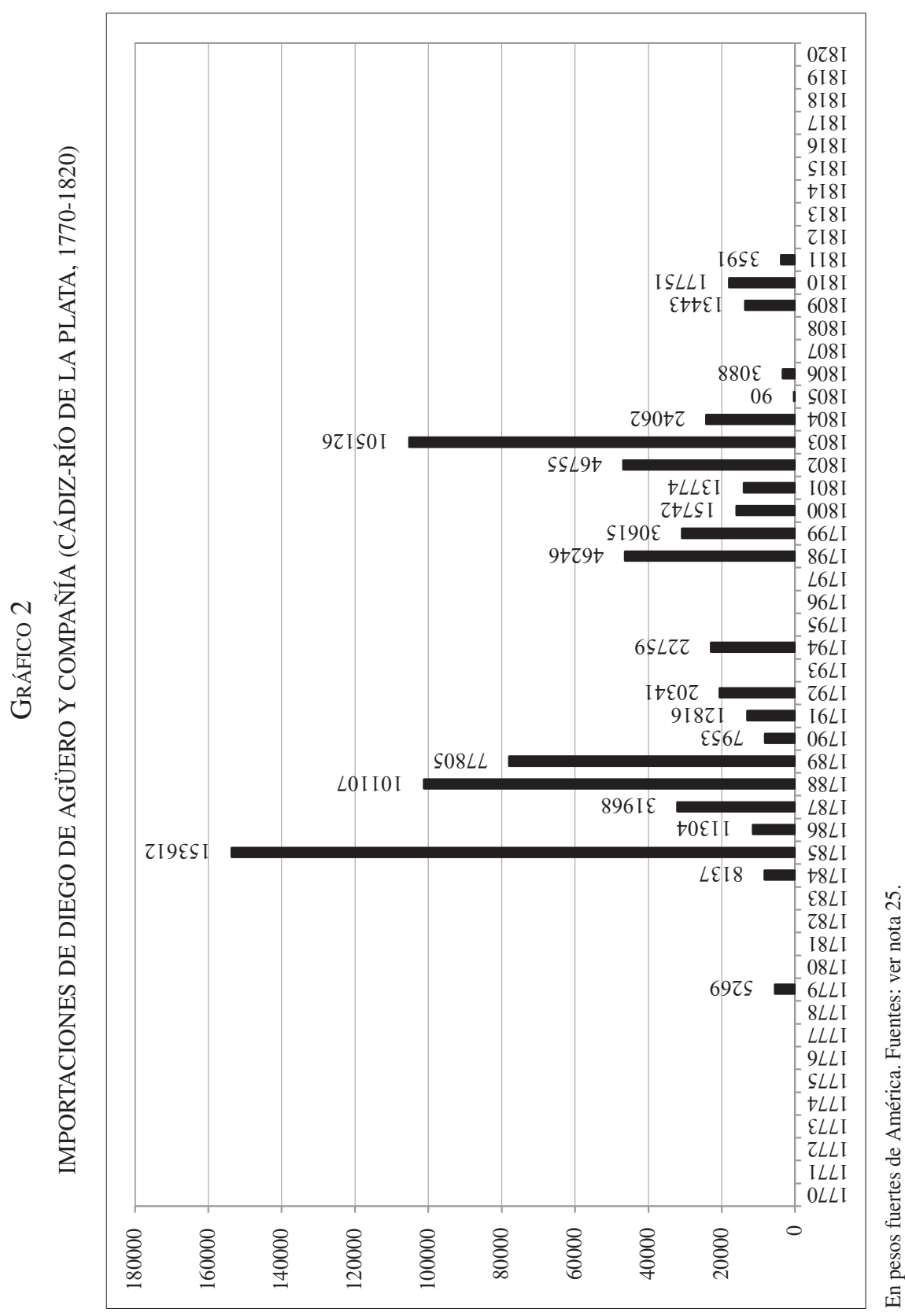


Aunque es retomado luego de la sanción del Reglamento de 1778, vuelve a detenerse en 1779, debido al inicio de la guerra anglo-española. Aunque Agüero continuó remitiendo caudales a Cádiz por la vía del Brasil, el impacto fue innegable, y apenas si se alcanzan los mismos volúmenes de 1773. Una vez restablecida la paz, en 1784 se observa un notable crecimiento, que luego decrece paulatinamente, a lo largo de la década de 1780, resultado de la agudización de la competencia desatada al interior del capital mercantil español, como fruto de la remisión a América de los stocks acumulados en la Península durante la guerra anglo-española de 1779-1783.

Por su parte, la década de 1790 muestra el movimiento contrario: un ritmo ascendente, que no detiene la guerra contra la Francia revolucionaria, y que lleva al máximo nivel de exportaciones de toda la historia de la compañía en 1796 (que se explica particularmente por el viaje de uno de los socios, Miguel Fernández de Agüero, a Cádiz ese mismo año, y con la remisión del capital necesario para sus compras allí). No obstante, el pico de 1796 marca, paradójicamente, el inicio del fin: la segunda guerra con Gran Bretaña sumirá a España, en general, y a la compañía Agüero, en particular, en una crisis sin precedentes, que se extenderá hasta la desaparición del Imperio. Desde entonces, las exportaciones acompañan las breves esperanzas coyunturales de recuperación (1802, de paz con Inglaterra; 18091810, expulsión de los franceses de la Península; 1814, última remesa, previa a la derrota de los realistas en el Plata).

Es decir que el ritmo mercantil de la compañía Agüero expresa el movimiento más general del comercio colonial español: por un lado, el grueso de las remesas se concentró en las décadas de 1780 y $1790(77 \%$ del total); por el otro, el impacto de las guerras y procesos revolucionarios incidió negativamente en su desarrollo, coincidiendo con los períodos de ausencia o reducción del volumen mercantil. ${ }^{28}$ Hipótesis que se ven confirmadas al sistematizarse el giro mercantil en el sentido contrario, es decir, a través de las importaciones que Agüero realizó desde el Río de la Plata.

Para construir el gráfico 2, hemos cuantificado las importaciones, siempre que fue posible, a partir del costo de las mercancías adquiridas en Cádiz (las que obtuvimos de diferentes tipos de documentación contable privada, como cuentas corrientes, recibos, facturas, etc.). Cuando no se conservó este tipo de fuente (lo que es muy común), hemos tomado el valor de aforo de las mercancías de las partidas de los registros de navíos.

28 García-Baquero, 1972. 
Naturalmente, dado que no podemos equiparar aforo con precio, hemos procedido a comparar las facturas de compra disponibles con los aforos, lo que dio como resultado que dicho valor poseía una depreciación respecto de los precios de compra en Cádiz de, aproximadamente, un $20 \% .{ }^{29}$ Es decir que nos hemos aproximado de manera más certera al volumen monetario que atravesó el Atlántico (el precio pagado por las mercancías en Cádiz) sumando ese porcentaje a cada uno de los aforos.

Como podemos ver, el movimiento replica al de las exportaciones de caudales. En primer lugar, Agüero recibe sus primeras mercancías en 1779, luego de haber remitido una buena cantidad de caudales a la Península, desde 1773. Sin embargo, como señalábamos, ese tímido comienzo fue abruptamente interrumpido por la guerra entre España e Inglaterra, que difirió hasta 1784 la reanudación del vínculo regular entre Cádiz y el Río de la Plata. La paz permitió la puesta en práctica del Reglamento de 1778 y el movimiento de un stock detenido acumulado que «inundó» de géneros los mercados americanos, lo que se expresa en el movimiento de Agüero: 1785, 1787 y 1788 representan los picos más altos de toda su carrera.

Paradójicamente, las guerras europeas parecen golpear más duramente a la importación de mercancías que a la exportación de caudales, probablemente porque, a la par que es alta la rentabilidad que ofrece especular con géneros en América en tiempos de guerra, se vuelve problemático dilatar los pagos pendientes en Cádiz, tanto a proveedores, transportistas como aseguradores. En ese sentido, los Agüero combaten el bloqueo inglés de la segunda guerra anglo-española con un nuevo viaje de uno de los socios, Miguel Fernández de Agüero, a Cádiz. Desde allí se traslada a Lisboa para mantener vivo el giro con Cádiz a través de la ruta portuguesa (Río de Janeiro, Lisboa y Ayamonte). No obstante, las irregularidades de la primera década del siglo XIX y el fin del vínculo entre Buenos Aires y la Península, en 1811, dan cuenta del colapso de la compañía junto con el fin del comercio colonial español.

Por su parte, la cuantificación de las importaciones nos permite evaluar el sentido que tuvo el flujo y movimiento de riquezas: un volumen aproximado de 753 mil pesos fuertes (un monto sustantivamente menor respecto del exportado) da cuenta de una balanza comercial deficitaria para el Río de la Plata.

29 La monarquía española era consciente de este desfasaje del valor de aforo, por lo que los derechos que cobraba al tráfico de mercancías (almojarifazgo y alcabala) poseían un $12 \%$ de aumento sobre ese valor, lo que acercaba el monto exigido a un precio de venta más cercano al manejado en los mercados. 
MARIANO MARTÍN SCHLEZ

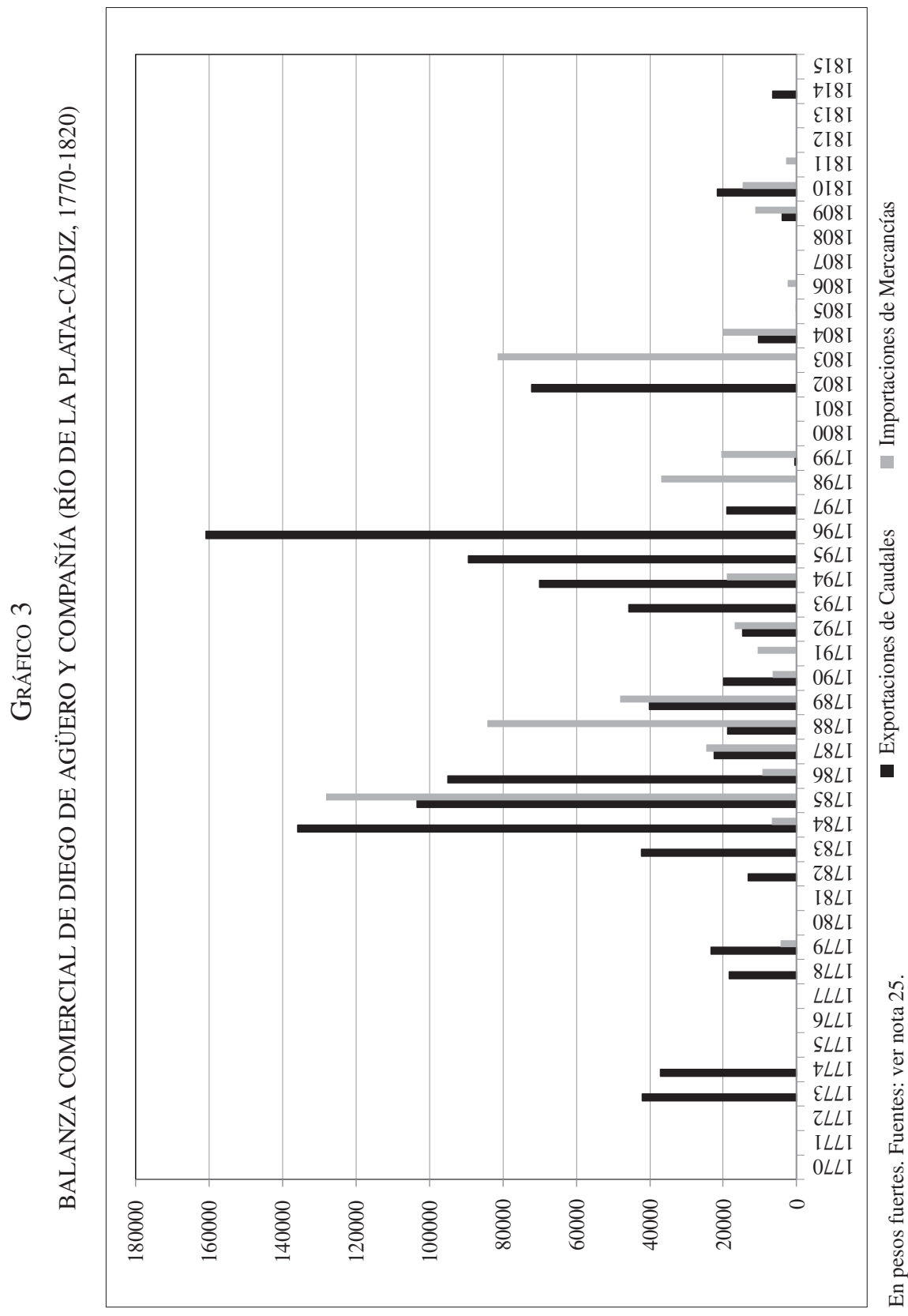


La balanza comercial de la compañía Agüero nos permite concluir que el tráfico dinamizado ofreció un saldo positivo estimado en 410.279 pesos fuertes, que tuvo como destino Cádiz. Monto que debemos considerar, una vez más, como un piso mínimo, en tanto, por un lado, no cuantifica el aporte de los frutos del país exportados y, por el otro, no tiene en cuenta la ganancia apropiada por Agüero, también obtenida del proceso de circulación y acumulada en Buenos Aires, sin ser remitida a España.

En este sentido, en tanto esa diferencia comercial favorece a las exportaciones por sobre las importaciones, podemos concluir que Agüero actuaba como un elemento de transferencia de valor desde la colonia rioplatense hacia el corazón metropolitano: tomando el flujo de valor como un todo, mientras que el $39 \%$ correspondió a importaciones, el $61 \%$ perteneció a las exportaciones, por lo que se desprende que la diferencia del $22 \%$ obtenida en la circulación tuvo como destino el puerto de Cádiz (más allá de que luego haya seguido viaje hacia el extranjero, como nos hará suponer el detalle del contenido del comercio estudiado). ${ }^{30}$

\section{El contenido del comercio. Importaciones al Río de la Plata}

Para graficar el contenido del tráfico de Agüero, del que da cuenta la misma documentación que venimos trabajando, apelaremos a la tradicional clasificación entre mercancías exportadas e importadas y dividiremos los productos de acuerdo a su lugar de producción: «extranjeros» (provenientes de las principales naciones europeas), «nacionales» (fabricados en los límites de la España peninsular) y «frutos del país» (producidos en América). Individualizaremos, asimismo, el tipo específico de metales preciosos (oro y plata, en sus diferentes variantes), y clasificaremos los productos importados atendiendo a su carácter de mercancía manufacturada (a las que dividiremos en géneros textiles y otros rubros) o agraria.

Como señalamos, el primer elemento a dilucidar en torno a las mercancías importadas es su lugar de producción, en tanto nos ayuda a comprender las características específicas del giro de Agüero.

Los datos aportados por los registros de navíos muestran que mientras que el $58 \%$ de las mercancías traficadas fueron producidas en el extran-

30 Porcentaje al que arribamos luego de realizar la siguiente operación: Volumen monetario exportado - Volumen monetario importado = Diferencia mercantil luego del proceso de circulación en América. 
jero, el $42 \%$ restante fueron de producción española. Es decir que los productos extranjeros importados por Diego de Agüero superan casi en un $20 \%$ a los españoles, por lo que más de la mitad de las mercancías importadas desde la Península fueron producidas fuera de España, e introducidas en Cádiz para ser reexportadas desde allí al Río de la Plata.

Asimismo, el origen de las mercancías extranjeras nos permite evaluar la importancia de las diferentes naciones europeas en el tráfico dinamizado por la compañía Agüero con sus proveedores. ${ }^{31}$ Entre ellas se destaca, en primer lugar, la actual Alemania, con el $34 \%$ de las mercancías comerciadas, provenientes mayoritariamente de las ciudades de Hamburgo y Silesia. A la que le sigue Francia, que con el protagonismo de Bretaña, Rouén, París, Cambray, Nimes, Hoondschoote, Chalons y Lille, se queda con casi un tercio del total $(29,92 \%)$. Detrás de ellas se colocan Inglaterra $(23,74$ \%) y los Países Bajos (12,09 \%), donde se destacan Flandes y Brabante, que dejan a Italia con un aporte mínimo del 0,25\%.

Es decir que el origen nacional de las mercancías traficadas por Agüero expresa otra particularidad más general del comercio español: su carácter comisionista, en tanto naciones poderosas se ven obligadas a vender sus mercancías en Cádiz en virtud del monopolio, imposibilitadas aún para desarrollar un comercio directo con Sudamérica, pese a sus estructuras productivas más competitivas.

Por otro lado, pasando a otra de las características del contenido del tráfico, un análisis de las ramas productivas implicadas nos muestra un notable grado de especialización de la compañía Agüiero en el tráfico de manufacturas $(99,47 \%)$, en relación a un casi nulo aporte de mercancías agrarias $(0,53 \%) .^{32}$ Relación que encontramos tanto en la importación de manufacturas extranjeras $(99,61 \%$ del total) como españolas $(99 \%)$. Pasemos, entonces, a describir su composición.

31 Los datos pueden presentar un margen de error, en tanto los registros de navíos no siempre aclaraban el origen del producto, y una serie de bienes podía ser fabricado en diferentes ciudades (como los paños holandeses, ingleses o franceses, los ruanes y estopillas franceses y alemanes; los chamelotes ingleses y holandeses, el hilo italiano y de los Países Bajos o los listados de los Países Bajos, Francia y Alemania).

32 Las importaciones agrarias corresponden a unas escasas y aisladas importaciones de comestibles, particularmente aceite, vinos, chocolate (proveniente de Caracas y reexportado desde Cádiz) y canela. No obstante, es menester destacar que en el último arribo del navío de los Agüero, el «San Luis Beltrán», al Río de la Plata, fueron importadas 237 pipas de vino tinto, 20 pipas de vino blanco, 289 barriles de vino blanco, 800 botijas de aceite, 400 botijas de aceitunas, 300 balas de papel blanco, 126 bultos de efectos varios y 80 lastres de sal. Dado que no hemos hallado el registro de navíos correspondiente, y hemos extraído la información del Suplemento al Correo de Comercio de Buenos 


\section{Manufacturas extranjeras}

Una mirada atenta del enorme caudal de manufacturas extranjeras importadas por Agüero da cuenta de un segundo nivel de especialización, como resume el gráfico 4.

\section{GRÁFICO 4}

\section{MANUFACTURAS EXTRANJERAS IMPORTADAS POR DIEGO DE AGÜERO Y COMPAÑIIA (1770-1811)}

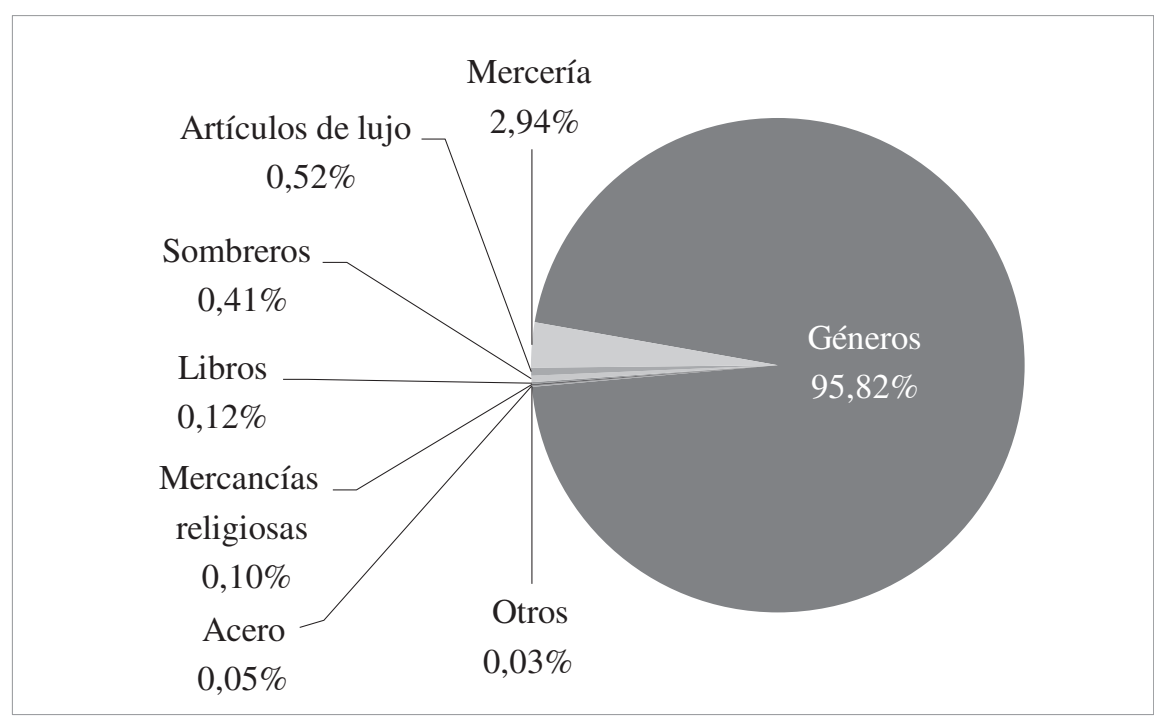

Según valor de aforo en Cádiz. Fuentes: ver nota 25.

Aquí observamos una abrumadora mayoría que prueba que Agüero se especializó en el comercio de géneros textiles: con un 95,82 \%, la presencia de las telas y confecciones sobrepasa elocuentemente a la mercería $(2.94 \%)$, artículos de lujo $(0,52 \%)$, sombreros $(0,41 \%)$, libros $(0,12 \%)$, mercancías religiosas $(0,10 \%)$ y acero $(0,05 \%)$. Veamos, antes de avanzar en conclusiones, cuáles eran específicamente los géneros comercializados.

Para reconstruir y medir la importancia de los diferentes géneros traficados apelamos también a las partidas de registros de navíos, que ofrecen información de los volúmenes, procedencia (aunque no siempre) y valor de aforo. 
Los datos vertidos prueban un tercer nivel de especialización, en tanto unos pocos géneros explican la estructura básica del total de los textiles importados, pese a su gran variedad. Nos referimos a las bretañas y a las platillas, seguidas en importancia por bayetas y ruanes. ${ }^{33}$ Este primer conjunto, de tan solo cuatro variedades, representó el $64 \%$ del total de géneros importados.

Las bretañas eran importadas de Francia (como su nombre lo indica, de la región de Bretaña). Su composición era variada, destacándose dos tipos: las contrahechas (angostas y entreanchas), de menor calidad y valor (36 y 55 reales la pieza de valor de aforo), y las legítimas (también, angostas, entreanchas y anchas), con un valor de aforo de 36,50 y 70 reales la pieza. Ambas variedades, realizadas usualmente con una medida de 8 varas por pieza. Por su parte, los ruanes, provenientes de Silesia (en aquel entonces, parte de Prusia), un tanto más baratos, eran llamados legítimos o contrahechos, con un valor de aforo de 4 reales y medio la vara, usualmente cortados en piezas de a 55 y 72 varas. Asimismo, las bayetas eran de los géneros más caros que los Agüero comerciaban, en su variante de pellón o de cien hilos (660 reales la pieza), de dos frisas (486 reales) y de tajuela (372 reales). Producidas en Inglaterra, eran usualmente cortadas en piezas de entre 40 y 44 varas. Finalizando este primer grupo encontramos a las platillas reales, también costosas (entre 160 y 170 reales), se comerciaban en diferentes colores, generalmente cortadas de a 38 1/2 varas la pieza.

Por su parte, los tripes de pelo y de lana, bramantes, estopillas, paños, sargas de Nimes y calamacos aportan un $22 \%$ al total de géneros importados, y junto al primer grupo explican el $86 \%$ del total de la estructura de géneros importada por Agüero.

Los tripes de pelo provenían de Francia, había de primera y de segunda, lisos y rayados, y su aforo rondaba los 20 reales la vara. Su variedad en

\footnotetext{
Aires (30 de junio de 1810), no hemos incluido este buque en las estadísticas. Puede especularse que este cargamento, con una fuerte presencia de productos agrarios, se encuentra vinculado a las dificultades señaladas por Blas Agüero para cargar mercancías en Cádiz, ocupada por los franceses. De todas maneras, esta importación, aislada y en un período de plena crisis revolucionaria, aunque hubiera aumentado levemente los porcentajes mínimos de productos agrarios españoles importados, de ninguna manera cambia el patrón general que hemos expuesto.

33 Para construir este acápite e identificar cada tipo de género apelamos al Nuevo tesoro lexicográfico de la lengua española (NTLLE), disponible en http://ntlle.rae.es/ntlle/SrvltGUILoginNtlle (consultado el 15 de mayo de 2013). Asimismo, la bibliografía especializada en moda y vestimenta nos ha permitido acceder no solo a sus usos y características, sino también a la región específica de producción cuando los registros de navíos no lo señalaban. Solo a título de ejemplo, véase Michavila Díaz, 2007; Berón, 2011.
} 


\section{GRÁFICO 5}

GÉNEROS EXTRANJEROS IMPORTADOS POR DIEGO DE AGÜERO (1770-1811)

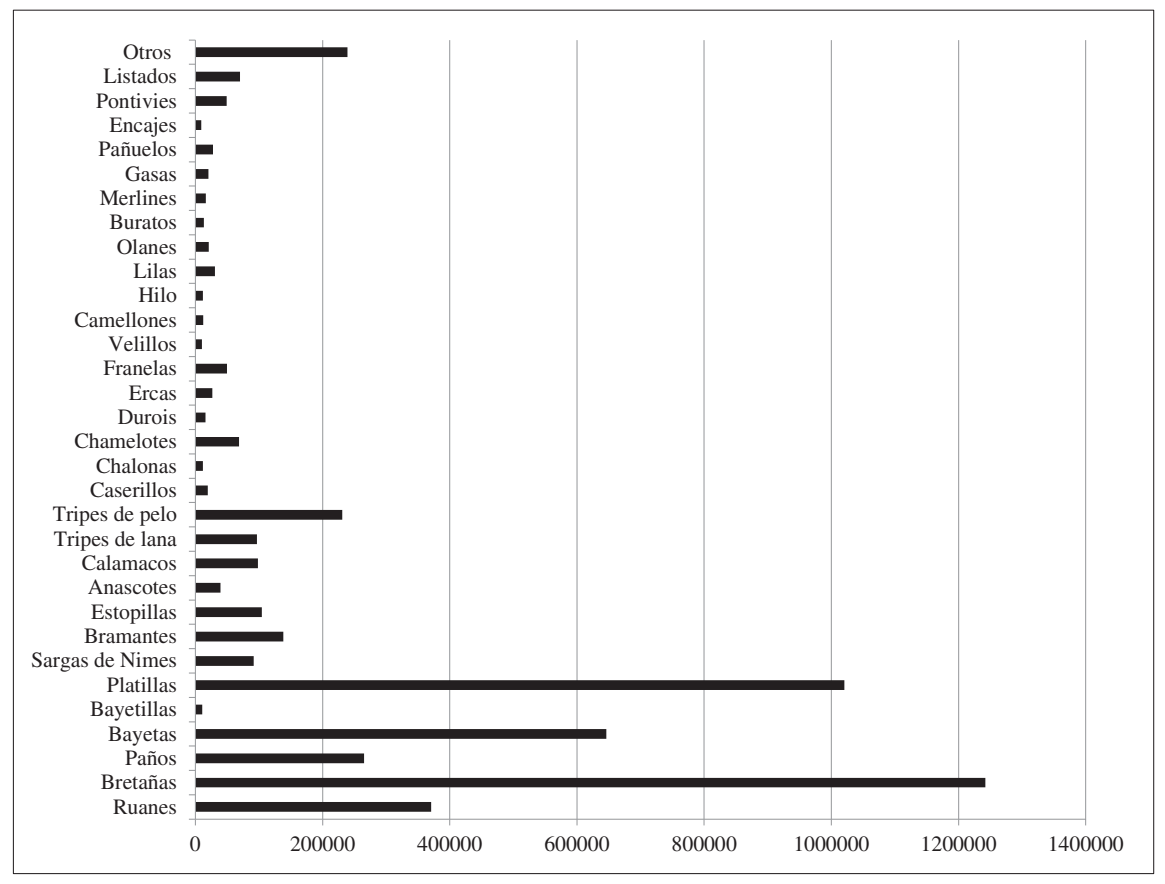

Según valor de aforo en Cádiz. En reales de vellón. Fuentes: ver nota 25.

lana también era fabricada allí, pero su valor se reducía a la mitad. Los bramantes, como se los llamaba, tenían un valor menor, de 7 reales y medio la vara, la variedad florete, y 4 reales los crudos. Por su parte, las estopillas venían en diferentes variedades, con diferentes valores por pieza, generalmente de 8 varas y media: clarines ( 56 reales), olanadas ( 75 reales) y labradas (60 reales). Todas podían ser lisas o rayadas, en diferentes tonos. De la misma manera, los paños tenían una importante diversidad, tanto en su origen como en sus calidades. Los que llegaban desde Inglaterra eran de primera calidad (125 reales vara), de segunda ( 21 reales vara) y de tercera (17 reales vara); y los de Holanda poseían un aforo de 45 reales vara. Asimismo, llegaban paños entrefinos de Carcasona, desde Francia, también de primera calidad (entre 40 y 50 reales la vara) y otros más «ordinarios», 
o de segunda (21 reales vara). Y también buena parte de las importaciones correspondía a los paños de seda, con un valor de aforo de 70 reales la vara.

Otro de los géneros más costosos eran las sargas de Nimes, también conocidas como piezas eternas o perdurables. Las de mejor calidad tenían un alto valor de aforo, de 400 reales la pieza de 32 varas, bajando hasta 225 reales las de segunda calidad. Valor similar, este último, al de los calamacos, que eran fabricados mayoritariamente en lana, con un valor de 165 reales los lisos, y de 230 los rayados.

El $14 \%$ restante de las importaciones se componía de una enorme variedad, conformada por buratos, merlines, gasas (de seda y de hilo), pañuelos (de algodón, seda e hilo), encajes (de hilo, importados de Flandes), pontivies, listados (provenientes de Francia y Flandes, hechos en hilo, estambre y lana), olanes (provenientes de París, en su variedad batistas y clarines), lilas, hilo (de Génova y de Flandes), camellones (de Inglaterra), velillos (de hilo), franelas, ercas (angostas y anchas), durois (de Inglaterra), chamelotes (de Holanda e Inglaterra), caserillos, anascotes y bayetillas.

A los que debemos sumar además las variedades que hemos agrupado en el rubro «otros», entre las que encontramos pequeñas cantidades de listones, melindres, sarguillas, felipichines, grodetur, sempiternas, satinetes, medias sarasas, serafinas, morleses, lanillas, crespones, cuvicas y estameñas frailescas.

Las manufacturas extranjeras importadas son, como vimos, una parte ínfima y variada de las importaciones realizadas por los Agüero. De hecho, apenas pudimos agruparlas según amplios rubros, para organizar la exposición.

El único rubro que sobresale es el de mercería, que abarca aproximadamente la mitad del total, compuesto de botones, hebillas, dedales de metal y hierro, tijeras, cascabeles, navajitas, agujas de coser, alfileteros, cordones para zapatos, moños de seda, cajas de cartón y diversas mercancías más. Muy por detrás tenemos a los artículos de lujo (diferentes tipos de cajas y cigarreras, carros de Amiens, dos pianos - uno proveniente de Sajonia-, dos relojes grandes, espejos de marco de cristal); y los diferentes tipos de sombreros (predominando los de castor, aunque también de paja y de cartón). Y ya en menor cantidad llegaban los libros (entre los que se destacan los 79 tomos de la Historia Eclesiástica de Fleuri, valuados en 1000 reales), el acero y lo que hemos llamado mercancías religiosas, en donde agrupamos todo tipo de estampas, cruces y rosarios. 


\section{GRÁFICO 6}

\section{MANUFACTURAS EXTRANJERAS IMPORTADAS (S/GÉNEROS)}

POR DIEGO DE AGÜERO (1770-1811)

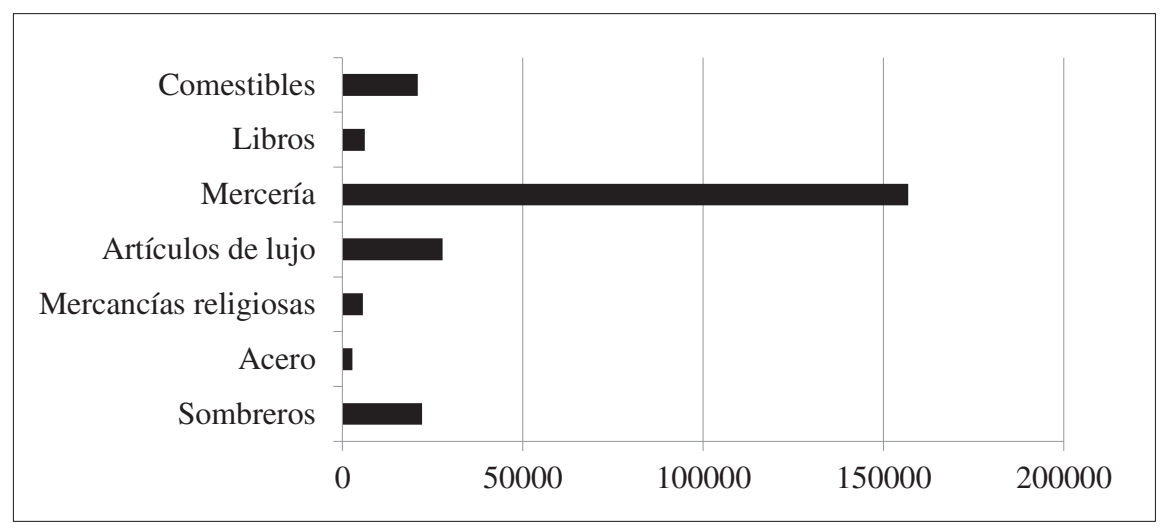

Según valor de aforo en Cádiz. En reales de vellón. Fuentes: ver nota 25.

Esto por solo mencionar las mercancías que hemos clasificado de alguna u otra manera. A ellas debe sumársele una variedad de productos que van desde paraguas hasta pequeñas limas para las uñas, navajas para afeitar, cuchillos, jaboneras, juguetes («relojitos fingidos para niños»), candados, vasos, compoteras de cristal, juegos de mapas, cucharas de estaño y hierro, bandejas, peines, juegos de naipes, abanicos, anteojos y especias, como la canela, que completaban las importaciones de Agüero.

\section{Manufacturas españolas}

En la segunda mitad del siglo XVIII, la economía española producía una importante cantidad de mercancías, a lo largo y ancho del territorio peninsular, que eran comerciadas tanto en el espacio nacional europeo, como exportadas desde allí a las colonias. ${ }^{34}$ Como hemos visto, los productos españoles representan, en el giro de los Agüero, una porción menor a la de los extranjeros, aunque alcanzan un $42 \%$ del total de mercancías importadas. Veamos, exactamente, cuál fue su contenido.

34 Fontana, 1982. 


\section{GRÁFICO 7}

\section{COMPOSICIÓN DE MANUFACTURAS ESPAÑOLAS IMPORTADAS \\ POR DIEGO DE AGÜERO (1770-1811)}

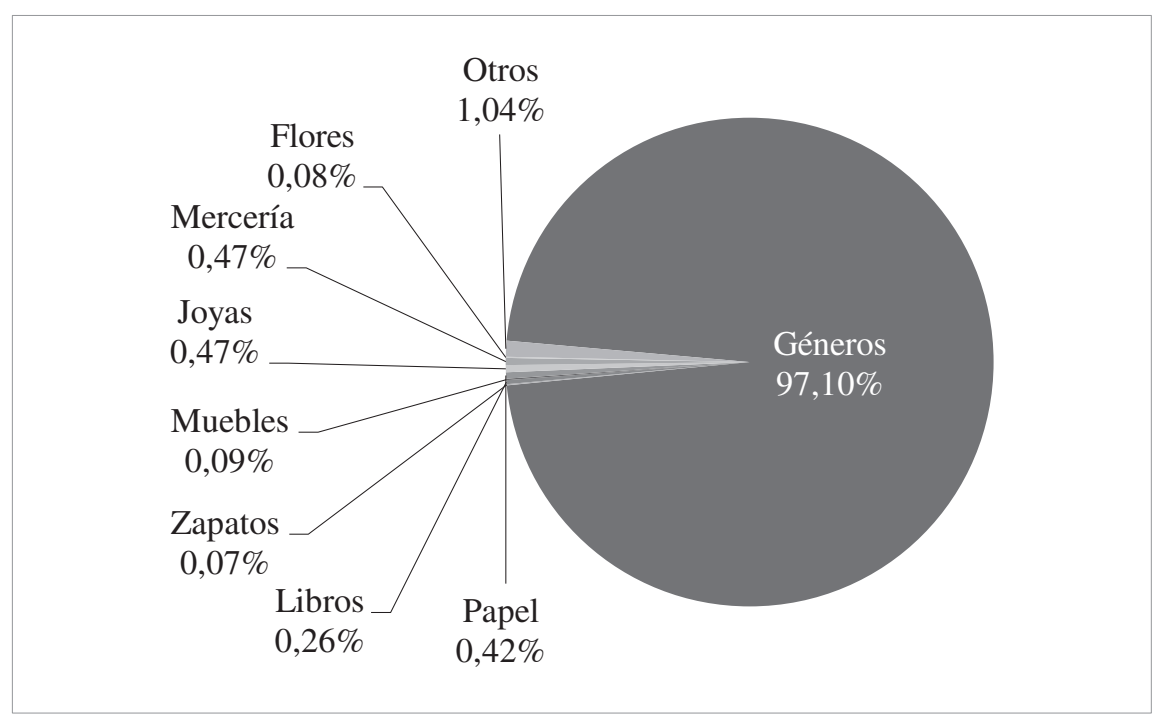

Según valor de aforo en Cádiz. Fuentes: ver nota 25.

Tal como lo muestra el gráfico 7, y al igual que lo ocurrido en el caso de manufacturas extranjeras, el giro de Agüero se caracteriza por un predominio absoluto de los géneros, los que representan el 97,10\% de las importaciones, por sobre la mercería $(0,47 \%)$, las joyas $(0,47 \%)$, el papel $(0,42 \%)$, los libros $(0,26 \%)$, los muebles $(0,09 \%)$, las flores $(0,08 \%)$, los zapatos $(0,07 \%)$ y un variado conjunto de efectos $(1,04 \%)$. Veamos, en primer lugar, la composición de los textiles españoles, para evaluar también si existe algún grado de especialización en algunos de ellos. ${ }^{35}$

35 Consideramos como géneros españoles a los que así aparecen consignados en los registros de navíos, aunque esto no siempre refleje tan fielmente su verdadero origen. Ciertas telas, como las platillas de Hamburgo y las indianas del norte de Europa, las que eran importadas y pintadas finalmente en Cataluña, lo que las habilitaba a ser presentadas a la Real Hacienda como género nacional. De hecho, todas las platillas que aparecen en las partidas de registro como productos españoles tienen la aclaración de haber sido pintadas o teñidas en Cataluña, y hasta se aclara en algunos casos que llevan el sello de la real aduana para certificar su carácter de bien nacional en los puertos. 
GRÁFICO 8

GÉNEROS ESPAÑOLES IMPORTADOS POR DIEGO DE AGÜERO (1770-1811)

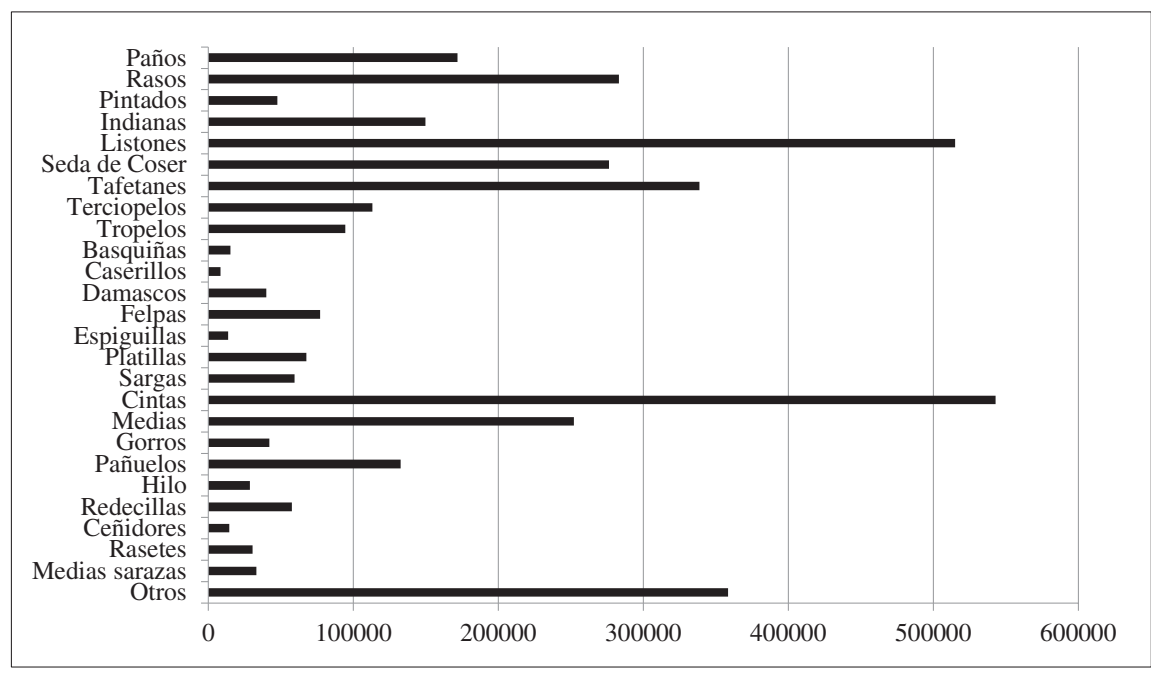

Según valor de aforo en Cádiz. En reales de vellón. Fuentes: ver nota 25.

Aunque la estructura de géneros españoles importados es más diversificada que la de extranjeros, las cintas (cintería) y los listones (listonería) suman poco menos de un tercio $(28 \%)$ del total. Ellas eran producidas en diferentes lugares de la Península, con diferentes tipos de telas, en variados colores y tamaños. En el grupo de las cintas se destacan las de agua, de ribetillo angosto, de terciopelo, de hule, de raso, de tisú (tipo específico de cinta de seda), de lavón, de seda, de plata, de platilla, de petatillo, de granito y de coleta. Otro grupo era llamado de acuerdo a algunas de sus características, como las acolchadas, pintadas, jaquelillo, aprusianadas o prusianas, chinescas, afondadas, grisetas o agrisatadas, bocadillo, las de espejuelos, labor a la francesa y las de la unión. Un grupo de cintas eran llamadas falsas, y algunas de ellas eran matizadas con plata, mientras que otras eran estampadas o con adornos en plata. Algunas venían con tres guardillas, y otras con nueve y también se destacaban las llamadas piezas dobles. Su ancho variaba desde las pequeñas $\left(n .^{\circ} 20\right)$ hasta las más grandes $\left(n .^{\circ} 120\right)$.

Las cintas de agua eran producidas en Granada y en Sevilla, de donde también provenían las de tisú, coleta, platilla, petatillo, piezas dobles, 
jaquelillo, griseta y bocadillos. Granada aportaba también las de raso y prusianas, mientras que las de ribetillo angosto provenían de Córdoba y las acolchadas y pintadas, de Valencia. Las cintas de plata y seda eran producidas en Barcelona, y algunas poseían un origen doble, como las cintas de tisú de Sevilla, con encajes y plata fina de Barcelona.$^{36}$ Naturalmente, sus valores eran muy variados, dependiendo de sus telas, su ancho (definido por su número), el largo (señalado, generalmente, en varas) y el peso (mayoritariamente, el volumen de las de seda se calculaba en libras). Las más costosas eran las cintas de seda, aforadas hasta en 400 reales la libra, aquellas que eran adornadas con plata, en una escala que arranca en los 30 reales.

Por su parte, la listonería no poseía una composición tan variada: producidas en Granada, variaban en sus colores y anchos, aunque no en las telas de su fabricación, generalmente hechas en raso y lavor. Sus tamaños iban desde el n. ${ }^{\circ} 15$ hasta el 100, extremos que difícilmente alcanzaban, constituyéndose el grueso de las importaciones de listones n. ${ }^{\circ} 20$ y 40 . Eran de menor valor que las cintas, y su valor de aforo iba desde los 10 reales hasta los 48, dependiendo del número de su ancho.

Luego de la cintería y listonería, Agüero se destaca en la importación de tafetanes, rasos, seda de coser y medias, las que suman un $31 \%$ del total y, junto al primer grupo, alcanzan casi el $60 \%$ del total de los textiles españoles. Es decir que seis variedades de géneros (sobre un total de más de veintiséis, que incluye al rubro «otros», que contiene una variopinta y numerosa composición) abarcan más de la mitad de las importaciones.

Los tafetanes eran telas fabricadas en Priego, Requena, Sevilla, Valencia y Málaga, venían en varios colores y su aforo oscilaba entre los 7 y los 20 reales la vara, dependiendo si se trataba de ordinarios, simples o dobles. Por otro lado, los rasos eran producidos en Valencia, en diversos tipos (matizados, dobles, rasolinos, prusianos, cartolinos), mayoritariamente hechos de seda. Su aforo iba de los 16 a los 32 reales la vara, y se hacían de colores variados. Por su lado, la seda de coser a la calabresa, proveniente de Murcia y Granada, era uno de los textiles más costosos, moviéndose entre los 60 y los 100 reales la libra, dependiendo de su carácter de ordinaria, joyante o surtida. Finalmente, las medias se caracterizaban por una variada composición: para hombre y para mujer; niños y adultos; de seda, hilo, lana, raso y algodón; en diferentes estilos (a la limeña, lisas, rayadas), colores y calidades (ordinarias, de primera, de segunda, inferiores). Su

36 Tanto para describir las diferentes variedades de mercancías, como para datar su fabricación hemos apelado a los propios registros de navíos, los que ofrecen dicha información. 
procedencia era también nutrida: Galicia (hilo), Barcelona y Cataluña (lana y seda), Cádiz (seda), Granada y Valencia. Las más costosas eran las de seda, valuadas entre 120 y 450 reales la docena; mientras que las de algodón o raso oscilaban entre los 130 reales y las de lana 150 reales.

Un tercer grupo de textiles estaba conformado por paños, pañuelos, indianas, terciopelos, tropelos, felpas, platillas, sargas y redecillas. Los paños tenían una procedencia y calidad diversa: producidos en Barcelona, Valencia, San Fernando y Guadalajara, había comunes, de primera, de segunda y de tercera, finos, entrefinos y de seda. Sus aforos, naturalmente, también eran muy diferentes, desde los más costosos (84 reales vara los de San Fernando y 75 los de las Reales Fábricas de Guadalajara) hasta los de menor valor (17 reales, los de tercera). Por otro lado, en la producción de pañuelos, situada en su gran mayoría en Barcelona, aunque también en Sevilla, predominaban los más costosos de seda (entre 50 y 150 reales la docena, dependiendo de su calidad), por sobre los de hilo o algodón (que rondaban los 70 reales) y los que poseían algunas características singulares, como la de ser estampados, pintados sobre platillas o sobre caserillo. También las indianas eran fabricadas en Barcelona, hechas de algodón, oscilando su valor entre los 6 y los 8 reales la vara. Por su parte, los cortes de terciopelo provenían de Valencia, fabricados lisos, rayados y labrados, aunque una pequeña proporción también tenía su origen en Cádiz. Su valor promediaba los 50 reales la vara, y eran muy solicitados para la confección de ropa de hombre y de mujer. También de Valencia eran los tropelos, lisos y labrados, y las felpas, confeccionadas mayoritariamente aterciopeladas, lisas y labradas, en diversos colores (ambos géneros rondaban los 40 reales la vara). E incluso las redecillas llegaban desde Valencia, hechas de hilo, de granito, de unión y de seda, con un valor que iba de los 100 a los 200 reales la docena. Las sargas eran otro de los géneros allí producidos, aunque en su gran mayoría eran fabricadas en Málaga, variando su aforo entre los 16 y 28 reales la vara.

Por último, las importaciones de géneros textiles se completan con un variado conjunto formado por pintados, basquiñas, caserillos, damascos, espiguillas, gorros, hilo, ceñidores, rasetes y diversos tipos de telas y confecciones que agrupamos bajo el rubro de «otros». En los registros no aparece referencia a la procedencia de los pintados, con la sola excepción de una partida procedente de Chiclana, aunque es probable que todos hayan llegado de Cataluña. Diferentes telas, como el algodón, pertenecían a este grupo (como las platillas a las que ya nos referimos), que tenía un valor estimado 
en los 10 reales la vara. Los cortes de basquiñas, o también llamados de nobleza, eran realizadas en raso, musulmana o listado, y tenían un alto valor de aforo que iba de los 200 a los 300 reales la pieza. Por su parte, los damascos y espiguillas, fabricados en Valencia, eran más baratos, rondando los 20 y 30 reales la vara. Asimismo, la gran mayoría de los gorros eran fabricados en Barcelona, aunque una parte también provenía de Sevilla y Granada. Su composición era diversa: sencillos, dobles, de seda, de algodón, de hilo, además de los sombreros de castor, que representaban un grupo bien diferenciado. Por su parte, los hilos eran producidos en Córdoba, Granada y Barcelona, en varios colores. Los ceñidores llegaban desde Barcelona y Valencia, mientras que los rasetes eran de Valencia, lisos y labrados, y los caserillos venían pintados y en formato de pañuelos. Por último, Agüero importó, más bien esporádicamente, anafayas, camisas de puntiví, bayetones, cartolinas, piñuelas, chupas, lienzos, musulmanas, blondas, belillos, cordones, muselina, cotillas, bayetillas, delfinas, melanias, mexicanas, cañuelas, olandes, morleses, franelas y angaripolas.

El resto de las manufacturas representan, como ya hemos dicho, una parte ínfima de las importaciones, y a diferencia de lo que ocurre con los géneros, encontramos que su composición es absolutamente variada, sin observarse especialización alguna.

Esta enorme diversidad se expresa en que el mayor grupo de mercancías es, justamente, aquel que denominamos «otros» y que agrupa productos tan disímiles como obras de arte (una pintura con la imagen de la Virgen María), una campana de metal o un torno para fabricar fideos. Sin embargo, existe un conjunto de mercancías que pueden agruparse en diferentes rubros, como mercería (botones, tachuelas, bolsas para dinero, charreteras), joyas (aros, gargantillas y anillos de diamantes), papel (de Cataluña), zapatos (botas, zapatos de seda de mujer y comunes, hechos en Cádiz), muebles (cama y cómodas) y libros, principalmente de autores católicos.

\section{Productos agrarios brasileños}

Pese a que el grueso de las importaciones de Agüero ya ha sido descrito, en tanto no solo resumen la enorme mayoría de su volumen sino también el grueso de su tiempo activo (1770-1811), es menester señalar la transformación provocada luego de la Revolución de Mayo (1810), y que se extendió hasta aproximadamente 1817. Porque mientras que las guerras europeas (sobre todo la de 1796) obligaron a los Agüero a comerciar 


\section{GRÁFICO 9}

MANUFACTURAS ESPAÑOLAS IMPORTADAS

(CON EXCEPCIÓN DE GÉNEROS) (1770-1811)

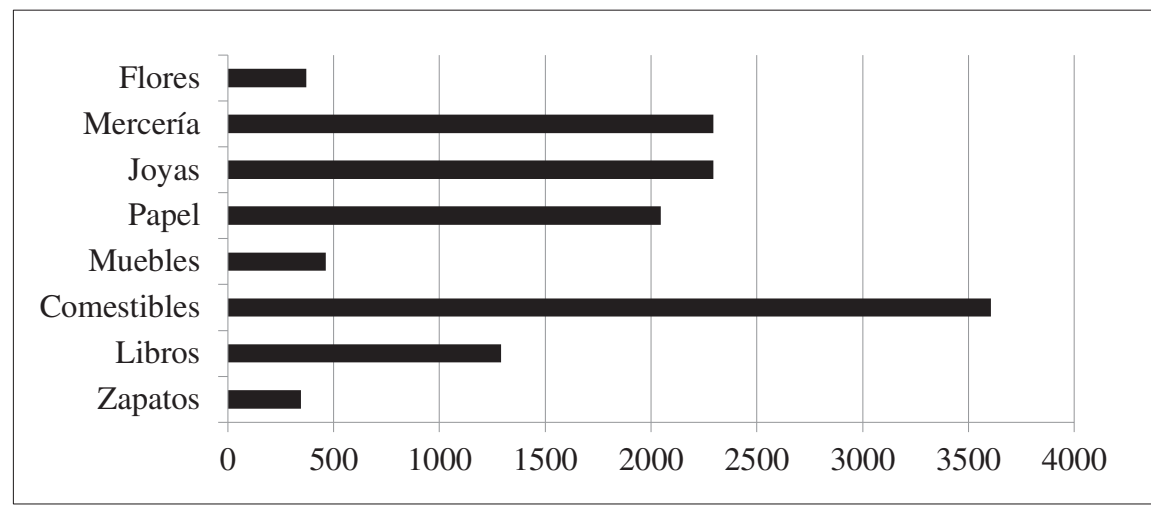

Según valor de aforo en Cádiz. Fuentes: ver nota 25.

desde Lisboa, y a aumentar su caudal de frutos americanos, las revoluciones americanas condenaron a sus descendientes a dinamizar un comercio de cabotaje entre Buenos Aires y las costas brasileñas.

Quebrado el eje Potosí-Buenos Aires-Cádiz, la sociedad de Diego de Agüero y Miguel Fernández de Agüero abandonó sus actividades comerciales tradicionales, y quien continuó a la cabeza del giro fue Blas de Agüero (hijo de Diego y primo de Miguel), comerciando mayoritariamente mercancías agrarias rioplatenses y brasileñas entre ambas costas sudamericanas. Aunque se trata de una historia diferente a la que hemos venido estudiando, y el estudio de este tráfico requiere de una observación más detallada de fuentes alternativas, los datos recopilados dan cuenta de un giro que vinculaba, regularmente, a Buenos Aires, Río de Janeiro y Bahía de Todos los Santos.

Dado que la serie de registros de navíos de Buenos Aires finaliza con la Revolución de 1810, para observar el movimiento comercial posterior con el Brasil apelamos a los Termos de Entrada y Salida de embarcaciones del AGRdJ, y a las entradas y salidas de mercancías, e informes a la capitanía del puerto de Buenos Aires, del AGN-A. Una sistematización de estas nuevas fuentes nos permite acceder a las mercancías traficadas y sus volúmenes físicos, además de los años en que viajaron, el navío en que lo 
hicieron y el comerciante que la remitió. Sin embargo, no nos permiten acceder ni a los comerciantes que vendieron a Agüero los productos en Brasil, ni al valor monetario (o precio estimado) de las mercancías. Veamos un resumen que pondera las mercancías de acuerdo con la cantidad de veces que fueron importadas.

Como muestra el cuadro 1, luego de la Revolución de 1810 Blas Agüero importó desde Río de Janeiro y Bahía de Todos los Santos, fundamentalmente, productos agrarios, destacándose el azúcar, el arroz, los cueros (de novillo, tigre y otras especies; además de los de desecho), el tabaco, los dulces, el aguardiente, el sebo, las chapas, el almidón, la caña y otros productos en menor cantidad. No obstante, también fueron parte del giro productos para la construcción (tixolos), cera, géneros (lienzos de algodón, ovillos de hilo), madera y sus derivados (platos, remos), armas (escopetas y espadas) y, finalmente, efectos, algunos de ellos europeos, además de pabilos, cocos para agua, guanterolas, barricas y tercerolas, entre otros productos. Evidentemente, estamos frente a un giro comercial de una naturaleza diferente al desarrollado por su padre, aunque su evaluación y ponderación merece un análisis más extenso.

Finalmente, y antes de pasar a la estructura de las exportaciones, es pertinente dejar en claro que los Agüero no se especializaron en la importación de esclavos, sea desde África o Brasil, limitándose a comprarlos, en pequeñas cantidades y generalmente por pedidos, en el Río de la Plata. ${ }^{37}$ Dato que no resulta menor a la hora de caracterizar las diferentes fracciones existentes al interior del capital mercantil rioplatense.

\section{Exportaciones desde el Río de la Plata}

Esta gran diversidad de mercancías fue intercambiada por una menos diversificada estructura de exportaciones, que se componía, básicamente, de metales preciosos y frutos del país. Una vez más, el contenido concreto de las exportaciones legales puede reconstruirse gracias a las partidas de los registros de navíos y la documentación privada de la compañía. Dado

37 Solo un documento de 1806 señala que Agüero habría introducido esclavos en un buque portugués, lo que le permitiría exportar frutos a puertos extranjeros. No obstante, es probable que, al igual que lo ocurrido con la citada importación de productos agrarios de 1810 , se trate de un caso excepcional, que no modifica el patrón general del comercio, aunque sí puede interpretarse como un intento por sostener el giro en tiempos de crisis. 


\section{Cuadro 1}

MERCANCÍAS IMPORTADAS DESDE PUERTOS BRASILEÑOS (1813-1816)

\begin{tabular}{|l|c|l|c|}
\hline \multicolumn{1}{|c|}{ Mercancía } & $\begin{array}{c}\text { Cantidad de } \\
\text { operaciones }\end{array}$ & \multicolumn{1}{c|}{ Mercancía } & $\begin{array}{c}\text { Cantidad de } \\
\text { operaciones }\end{array}$ \\
\hline Azúcar & 15 & Cuerdas de embina & 1 \\
\hline Arroz & 12 & Cocos para agua & 1 \\
\hline Cueros al pelo & 12 & Tirantes & 1 \\
\hline Cueros de desecho & 8 & Caña & 1 \\
\hline Lienzos de algodón & 7 & Cañete azúcar & 1 \\
\hline Tabaco & 6 & Barrica con asadas & 1 \\
\hline Dulces & 5 & Botellas de vino & 1 \\
\hline Aguardiente & 5 & Frasquines de curtidos & 1 \\
\hline Maderas y derivados & 5 & Fresadas & 1 \\
\hline Tixolos & 3 & Ponchos & 1 \\
\hline Sebo & 3 & Guanterolas & 1 \\
\hline Pavilo & 3 & Barricas & 1 \\
\hline Efectos & 3 & Tercerolas & 1 \\
\hline Gamelas de palo & 3 & Aceite & 1 \\
\hline Miel & 3 & Jabón & 1 \\
\hline Tablas & 3 & Cera & 1 \\
\hline Papel & 2 & Haciendas & 1 \\
\hline Almidón & 1 & Barriles & 1 \\
\hline Armas & 2 & Chapas & 1 \\
\hline Café & & Canastitas & 1 \\
\hline Chispa & & Bacalos de plata & 1 \\
\hline Tocino & 2 & 1 \\
\hline Ovillo de hilo & 3 & 1 \\
\hline
\end{tabular}

Según cantidad de operaciones de carga en navíos.

Fuentes: AGRdJ, Termos de Entrada y Salida de embarcaciones; AGN-A, Entradas y salidas de mercancías, Capitanía del Puerto de Buenos Aires (sala III). 
GRÁFICO 10

CONTENIDO DE LAS EXPORTACIONES DE DIEGO DE AGÜERO (1770-1816)

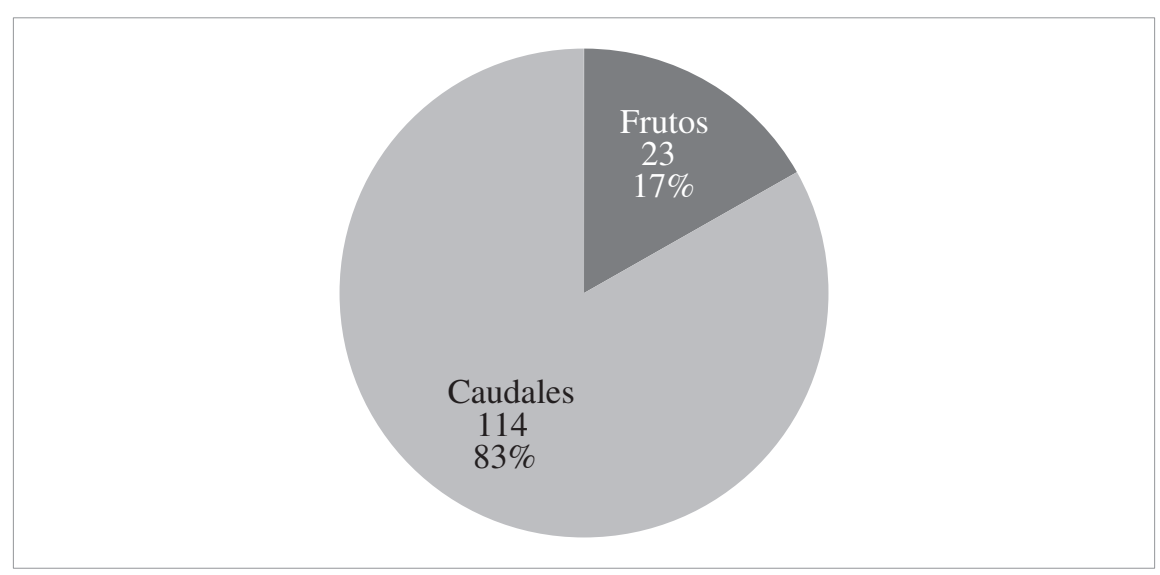

En cantidad de navíos. Fuentes: ver nota 25.

que, como ya señalamos, las partidas no consignan ni el precio ni el valor de aforo de los frutos cargados, hemos decidido ponderar el peso cuantificando la cantidad de navíos en que fueron cargados metales preciosos y productos americanos.

Como muestra el gráfico 10, la exportación de caudales predomina ampliamente por sobre la de frutos, con 114 navíos que trasladaron oro y plata, contra 23 que hicieron lo propio con producciones americanas. De hecho, la diferencia entre ambas mercancías se acrecienta en tanto lo que distingue al oro y la plata es su capacidad para atesorar una mayor cantidad de valor en proporciones menores de volumen, a diferencia del resto de los bienes, de mayor volumen y menor valor relativo. Es decir que, aunque no debemos menospreciar la importancia de la exportación de frutos, se trataba de una porción claramente minoritaria del giro. Pasemos, entonces, a su contenido concreto.

\section{Metales preciosos}

La mercancía que Diego y Miguel Agüero exportaron hacia la Península en mayor volumen fueron los metales preciosos (oro y plata) en 
sus diferentes formas (amonedado y en pasta). Como ya señalamos, 1.163.633 pesos fuertes viajaron desde el Río de la Plata a la Península Ibérica, en 101 navíos que atravesaron el Atlántico, entre 1773 y 1814. El contenido concreto de esa masa de valor (oro y plata en monedas, ${ }^{38}$ pasta $^{39}$ o piezas labradas ${ }^{40}$ ), lo resume el gráfico 11 .

\section{GRÁFICO 11 \\ REMESAS DE CAUDALES DE DIEGO DE AGÜERO \\ Y SUS SOCIOS A CÁDIZ (1770-1814)}

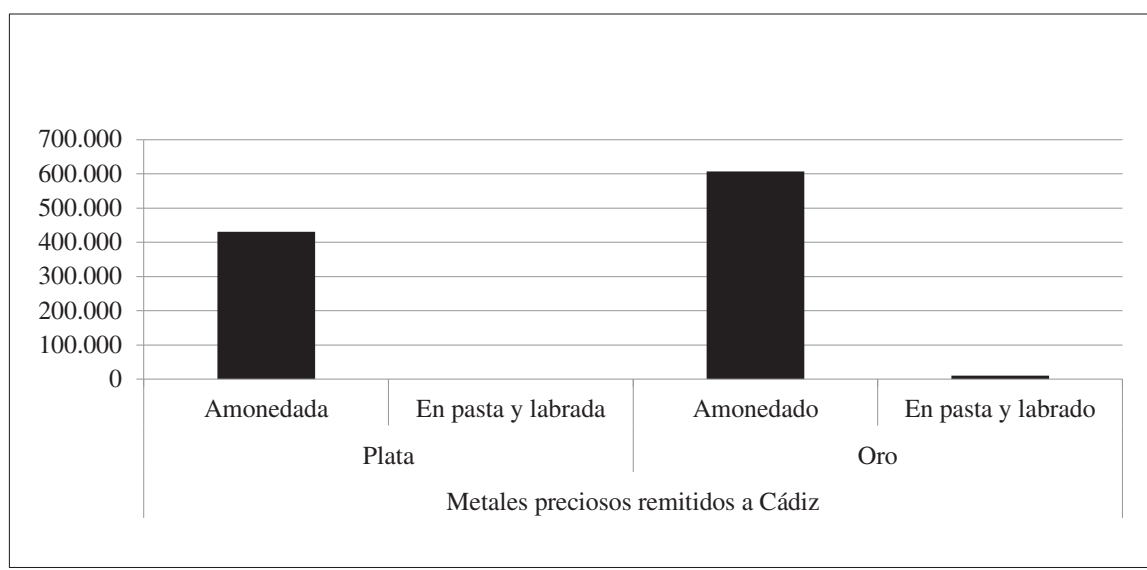

En pesos de América. Fuentes: ver nota 25.

Se observa un predominio del oro por sobre la plata, frente a un mínimo de remesas en oro en pasta (tejos de oro, en todas las oportunidades) y la inexistencia de envíos de plata en pasta y labrada. El envío de oro amonedado fue casi un $25 \%$ mayor al de la plata, hecho que puede explicarse por dos variables: los premios y los costos de los derechos a pagar en la Península. Por un lado, la enorme variedad de monedas existentes en el Imperio español, determinaba que, las más poderosas, obtuviesen un premio, es decir, que se paguen en el mercado real (mediante otra moneda) a

38 Metal precioso luego de haber recibido un tratamiento en una ceca, generalmente americana, que le dio el formato de moneda, sea de oro, como los doblones, o sea de plata

39 El metal fundido en forma de lingote o tejo.

40 Diferentes tipos de productos artesanales hechos en oro o plata, como, por ejemplo, un juego de candelabros. 
un valor mayor de lo que determinaba la ley. Dicho premio que pagaban las monedas de oro y plata en Buenos Aires y Cádiz variaba de acuerdo a la abundancia o escasez coyuntural de dichas mercancías y a la demanda que los comerciantes (mayoritariamente) tuviesen de ellas. Algunas estimaciones calculan, para la Buenos Aires de principios de la década de 1770, un premio del $3 \%$ para la plata, y de un $8 \%$ para el oro. ${ }^{41}$

Asimismo, como muestran los recibos de caudales elaborados por Miguel Agüero en Cádiz, mientras que la plata pagaba un $5 \%$ de derechos al Estado español, el oro abonaba el $1 \frac{1}{2} \%$. Finalmente, este interés por el oro que tenían los comerciantes de ambos márgenes del Atlántico, determinaba que muchos de los contratos firmados (con proveedores, aseguradoras de riesgos o prestamistas) estipulen en sus cláusulas que el retorno de América, para la debida cancelación del empréstito, debía realizarse en oro, lo que influyó, indudablemente, en este mayor porcentaje de oro por sobre la plata.

\section{Productos americanos}

Como ya hemos manifestado, los Agüero no se especializaron en la exportación de productos americanos, y sus niveles fueron ínfimos por lo menos hasta que la crisis del comercio colonial los obligó a evaluar la modificación de su patrón comercial tradicional (cosa que nunca llegó a ocurrir).

Entre los orígenes de su giro, en la década de 1770, hasta la crisis de 1796, Agüero remitió a la Península unos pocos envíos de frutos: cobre, pieles de chinchilla, cueros y cascarilla viajaron a Cádiz en ese período. De todas esas mercancías, solo 178 quintales de cobre eran de su cuenta y riesgo, mientras que el resto fueron embarcadas por pedido de terceros, limitando su rol al de cargador comisionista.

Sin embargo, la situación comenzó a transformarse con la crisis política de fines del siglo XVIII, que tenía paralizado al comercio atlántico entre puertos españoles. En sendos envíos de su propia cuenta y riesgo, realizados en el bergantín «San Felipe Neri» (originalmente español, simulado portugués para esquivar al enemigo inglés), en 1796 y 1799, Diego Agüero remitió a su sobrino, en Lisboa, una importante cantidad de frutos, que incluía desde los ya conocidos cueros y cascarilla, hasta plumas de

41 Álvarez, 1929, 86-91. 
avestruz, cacao y sebo. ${ }^{42}$ Desde entonces, la variedad y cantidad de frutos exportados creció, incorporando cueros de caballo, puntas y planchas de astas, yerba, sacas de lana, almendras, pieles y lana de carnero, además de suelas, crines, coyundas, pieles de guanaco, lenguas y cueros de alpaca.

Como señalamos al referirnos al tráfico de productos agrarios brasileños, este aumento de las exportaciones agrarias se profundizó luego de la Revolución de Mayo de 1810, hasta convertirse en el contenido privilegiado por la segunda generación Agüero en el Plata. A cambio de las mercancías importadas desde las costas del Brasil, Blas Agüero remitió cueros de novillo, de toro y de venado, trigo, ponchos cordobeses, lana y harina.

\section{Conclusiones}

El análisis del volumen, sentido y contenido del giro mercantil dinamizado por el comerciante español Diego de Agüero nos permite enumerar una serie de conclusiones particulares que expresan tendencias de carácter general del comercio atlántico colonial.

En primer lugar, respecto del marco temporal y los ritmos del tráfico, el giro de Agüero comienza a desarrollarse a principios de la década de 1770, en plena profundización del proceso reformista borbónico, y perdura hasta 1814 , en que las revoluciones de independencia jaquean su normal funcionamiento.

Vemos entonces que, si bien fue beneficiado por los cambios que colocaron a Buenos Aires en el centro del eje mercantil sudamericano, su actividad comercial era previa al Reglamento de 1778, y las bondades del «comercio libre», aunque le permitieron expandir sus negocios, lo hicieron de forma turbulenta. Es decir que el movimiento comercial nos muestra que, pese al notable crecimiento de la década de 1780, las sucesivas crisis bélicas, políticas y económicas que sufre España provocan un deterioro en su giro, que es finalmente liquidado al calor de los procesos revolucionarios de la segunda década del siglo XIX.

En segundo, los volúmenes comerciales prueban que estamos frente a uno de los principales comerciantes mayoristas del Río de la Plata, quien dinamizó, durante medio siglo, un giro superior al millón de pesos fuertes.

42 Dado que no se han conservado los registros de estos navíos, y accedimos a esta información a través de la correspondencia y cuentas corrientes de Agüero, carecemos del listado completo de mercancías y sus volúmenes. 
Asimismo, permitió con su tráfico que el valor puesto en circulación tuviera un sentido direccionado desde las colonias americanas hacia la Península Ibérica, aunque evidentemente dicha transferencia fue acompañada del desarrollo de un núcleo de acumulación local, fruto de su actividad cuentapropista.

En tercero, ya en lo que hace al contenido del comercio, nos encontramos con una estructura fundamental que respondía a la importación de manufacturas europeas (géneros textiles, en su inmensa mayoría), a cambio de metales preciosos (oro y plata amonedados), remitidos desde América periódicamente. A lo que debemos agregar una creciente incidencia de la exportación de frutos americanos, al calor de la profundización de la crisis del comercio colonial, que no llegó a modificar las bases del giro tradicional dinamizado en tiempos de tráfico «normal».

Finalmente, hemos mostrado cómo la Revolución de Mayo y la profundización de la conflictividad política mundial obligan a la compañía Agüero a reconvertir su giro para intentar sobrevivir, frente a la muerte de la ruta gaditana en el Río de la Plata. Fue así como se impone, en la segunda década del siglo XIX, un giro de cabotaje, entre Buenos Aires, Río de Janeiro y Bahía de Todos los Santos, de contenido mayoritariamente agrario. El vínculo con el Brasil aparece, de esta manera, como la antesala, o laboratorio a pequeña escala, del comercio que la Argentina desarrollará con Inglaterra a lo largo del siglo XIX.

Por su parte, más allá de las precisiones fácticas, el conocimiento detallado del caso Agüero resulta un aporte a aquellas historiografías globales y sistémicas que promueven un análisis holístico de la realidad histórica ${ }^{43}$ En primer lugar, lejos de una consideración posmoderna que supone una particularidad o singularidad irrepetible que imposibilita todo tipo de generalización, consideramos que Agüero nos permite aproximarnos a un conjunto social mayor, del cual resulta un observable privilegiado: los comerciantes atlánticos tardo-coloniales. A partir de un análisis global, que supera las divisiones políticas (estatales e Imperiales), y atendiendo a la compenetración e interacción de los factores locales y mundiales, debatimos algunas hipótesis sostenidas respecto del capital mercantil en los orígenes del sistema capitalista.

43 Para una aproximación a la historia global, la Atlantic History, la histoire croisée o la historia transnacional, véase Miller, 2015; Bailyn, 2005; Werner y Zimmermann, 2006, AAVV, 2006 y Fazio Vengoa, 2009. Un análisis sistémico clásico en Wallerstein (1979), quien retoma hipótesis y teorías planteadas por las escuelas de Braudel y Marx. 
En primer lugar, la especialización del tráfico de Agüero contradice la idea de que todo capital mercantil que se desarrolla tiende a su diversificación, y abona la idea de un creciente proceso de división del trabajo que caracteriza al desarrollo capitalista a nivel universal, y que incluye al comercio atlántico.

En segundo, el análisis del giro de Agüero (en relación al dinamizado por sus socios) relativiza el papel jugado por su subjetividad (o elección personal) en la estructuración de su comercio, el que da cuenta de las características productivas de las regiones conectadas, por un lado, y de la constitución de un sistema de organización socio-político específico, que requería del envío de metálico a la Metrópoli. Es decir que estamos frente a un capital mercantil con una notable especialización geográfica (dedicada exclusivamente al conectar Sudamérica y Cádiz) y comercial (con una acotada estructura de mercancías), que a través de la compra de géneros en Cádiz y su intercambio por metales preciosos en América produjo un millonario flujo de valor desde las colonias a la península Ibérica. Se trata, por lo tanto, de una fracción y una capa del capital mercantil que se diferencia de aquellas caracterizadas por una diversificada composición de sus negocios, rutas y mercancías. Por lo que el caso Agüero prueba que no puede descartarse el antiguo concepto de comerciante monopolista, más no sea, en los elementos aquí presentados, en lo que hace al aspecto más fenoménico, es decir, al desarrollo de un comercio exclusivo entre el Río de la Plata y Cádiz que dinamiza una masa de valor desde las Indias a la Península.

En este sentido, las características del giro que emprendía Agüero (especializado y exclusivo) explican las causas de su crisis terminal y el fracaso de sus intentos de supervivencia: el colapso del Imperio español barrió el vínculo entre Buenos Aires y Cádiz y obligó a sus herederos a apelar al comercio de cabotaje entre el Río de la Plata y Brasil, de contenido mayoritariamente agrario, en completa ausencia del antiguo giro monopolista. A manera de hipótesis, señalamos que, mientras que la ganancia de Diego y Miguel Agüero provenía de la vigencia del monopolio, es decir, de un comercio especulativo, dinamizado gracias a la vigencia política y a la intervención legal y militar del Estado español, luego de la Revolución de Mayo comienza a dinamizarse un comercio que tiene su motor y potencia en la competitividad de las mercancías agrarias rioplatenses, lo que da cuenta de la transformación social en curso que portaba el proceso independentista.

Es decir que la comprensión de la naturaleza de la Compañía Agüero, en particular, y de los comerciantes atlánticos, en general, requiere de una 
mirada holística (histórica, política, económica y social) a sus derroteros particulares, que dé cuenta tanto de sus características materiales y sus escalas de desarrollo, como de sus vínculos y redes a lo largo del planeta. Una aproximación de este tipo nos permite considerar que el llamado «cambio de ruta» de principios del siglo XIX, que llevó a los principales mercados sudamericanos de Cádiz a Londres, expresa en realidad una transformación más profunda en la naturaleza del comercio y de las relaciones sociales: de la especulación monopólica a la imposición del valor como regulador fundamental de la dinámica económica, como regidor principal del intercambio de mercancías competitivas en el mercado mundial.

En este sentido, cuando la crisis llegó a su punto álgido, al finalizar la primera década del siglo XIX, el monopolio del comercio intermediario fue puesto en jaque por la acción político-militar de los pueblos a los que explotaba, quienes se habían desarrollado económica y socialmente, y cuyo atraso constituía su base de existencia. A su vez, las cada vez más poderosas burguesías europeas, principalmente la inglesa y la francesa, aunque también la norteamericana, adquirieron el poder militar suficiente para destruir el monopolio, que se convertía, poco a poco, en letra muerta. Es decir que la historia del colapso de España como nación comercial dominante es la historia de la supeditación del capital comercial al capital industrial. En otras palabras, el fin de las condiciones que permitían la obtención de la ganancia comercial monopolista fue la apertura de los mercados americanos al tráfico internacional, lo que equivalió a la imposición de la ley del valor trabajo en el continente americano y la eliminación de la posibilidad de la obtención del sobreprecio que le permitía su reproducción al capital mercantil monopolista español.

Recibido el 6 de septiembre de 2014

Aceptado el 4 de febrero de 2015

\section{Bibliografía}

AAVV: «AHR Conversation: On Transnational History», American Historical Review, 111-5, Oxford, 2006, 1440-1464.

AAVV: La burguesía mercantil gaditana (1650-1868), Cádiz, Instituto de Estudios Gaditanos, 1976.

Aguado de los Reyes, Jesús: «Comercio, patrimonio, reputación y obra. Vivir y morir noblemente en Sevilla: los casos de Tomás de Mañara y Pedro La 
Farja», en Lobato, Isabel y Oliva Melgar, José María, El sistema comercial español en la economía mundial (siglos XVII-XVIII). Homenaje a Jesús Aguado de los Reyes, Huelva, Universidad de Huelva, 2013, 21-70.

Aillón Soria, Esther: Vida, pasión y negocios. El propietario de la Viña «San Pedro Mártir», Indalecio González de Socasa (1755-1820), Sucre, Archivo y Bibliotecas Nacionales de Bolivia, 2009.

Alfonso Mola, Marina: «El Diario Marítimo de la Vigía como fuente para la historia del comercio atlántico», en Lobato, Isabel y Oliva Melgar, José María, El sistema comercial español en la economía mundial (siglos XVII-XVIII). Homenaje a Jesús Aguado de los Reyes, Huelva, Universidad de Huelva, 2013, 413-466.

Álvarez, Juan: Temas de Historia Económica Argentina, Buenos Aires, El Ateneo, 1929.

Bailyn, Bernard: Atlantic History. Concept and contours, Cambridge, Harvard University Press, 2005.

Bernal, Antonio Miguel y García-Baquero González, Antonio: Tres siglos del comercio sevillano. Cuestiones y problemas, Sevilla, Cámara Oficial de Comercio, Industria y Navegación de Sevilla, 1976.

Bernal, Antonio Miguel: La financiación de la Carrera de Indias (1492-1824). Dinero y crédito en el comercio colonial español con América, Madrid/Sevilla, Consorcio Urbanístico del Pasillo Verde Ferroviario/ Fundación El Monte, 1992.

Berón, Lidia Teresita: Vestuario criollo (1770-1920), Buenos Aires, Dunken, 2011.

Böttcher, Nikolaus: Monopol und Freihandel. Britische Kaufleute in Buenos Aires am Vorabend der Unabhängigkeit (1806-1825), Stuttgart, F. Steiner Verlag, 2008.

Brading, David: Mineros y comerciantes en el México Borbónico (1763-1810), México, FCE, 1975.

Braudel, Fernand: Civilización material, economía y capitalismo. Siglos XV-XVIII, Tomo II, Madrid, Alianza, 1984.

Brenner, Robert: Mercaderes y revolución, Madrid, Akal, 2011.

Büschges, Christian y Langue, Frédérique: «Introducción. ¿Las élites de la América española, del éxito historiográfico al callejón interpretativo? Reconsideraciones», en Büschges, Christian y Langue, Frédérique (eds.), Excluir para ser. Procesos identitarios y fronteras sociales en la América Hispánica (XVII-XVIII), Madrid/Frankfurt, Iberoamericana/Vervuert, 2005, 9-22.

Bustos Rodríguez, Manuel: Cádiz en el sistema atlántico. La ciudad, sus comerciantes y la actividad mercantil (1650-1830), Madrid, Sílex Ediciones/ Universidad de Cádiz, 2005.

Chaunu, Huguette y Chaunu, Pierre: Séville et l'Atlantique, 1504-1650, Paris, SEVPEN, 1955-59. 
Crespo Solana, Ana (coord.): Comunidades transnacionales: colonias de mercaderes extranjeros en el Mundo Atlántico (1500-1830), Madrid, Ediciones Doce Calles, 2010.

Dalla-Corte Caballero, Gabriela: «La red social frente a la crisis del orden colonial: compensación judicial y vínculos de parentesco entre Buenos Aires y Cataluña», Colonial Latin American Historical Review, 9-3, Alburquerque, 2000, 347-377.

Fazio Vengoa, Hugo: «La historia global y su conveniencia para el estudio del pasado y del presente», Historia Crítica. Edición Especial, Bogotá, 2009, 300-319.

Fernández Pérez, Paloma: El rostro familiar de la Metrópoli. Redes de parentesco y lazos mercantiles en Cádiz, 1700-1812, Madrid, Siglo XXI, 1997.

Fisher, John: Commercial Relations Between Spain and Spanish America in the Era of Free Trade, 1778-1796, Liverpool, Centre for Latin American Studies, 1985.

Fisher, John: El comercio entre España y Hispanoamérica (1797-1820), Madrid, Banco de España-Servicio de Estudios, 1993.

Fontana, Josep: La economía española al final del Antiguo Régimen. Comercio y colonias, Tomo III, Madrid, Alianza, 1982.

Fontana, Josep y Antonio Miguel Bernal: El comercio libre entre España y América Latina, 1765-1824, Madrid, Fundación Banco Exterior, 1987.

Galmarini, Hugo R.: «Los españoles de Buenos Aires después de la Revolución de Mayo; la suerte de una minoría desposeída de poder», Revista de Indias, 178, Madrid, 1986, 284-290.

García de Flöel, Maricel: La oposición española a la revolución por la independencia en el Río de la Plata entre 1810 y 1820: parámetros políticos y jurídicos para la suerte de los españoles europeos, Berlín/Hamburgo/Münster, IT Verlag, 2000.

García Fuentes, Lutgardo: El comercio español con América, 1650-1700, Sevilla, Escuela de Estudios Hispano-Americanos, CSIC, 1980.

García-Baquero González, Antonio: Comercio colonial y guerras revolucionarias, la decadencia económica de Cádiz a raíz de la emancipación americana, Sevilla, Escuela de Estudios Hispano-Americanos, CSIC, 1972.

García-Baquero González, Antonio: Comercio y burguesía mercantil en el Cádiz de la Carrera de Indias, Cádiz, Diputación Provincial, 1989.

García-Baquero González, Antonio (ed.): La burguesía de negocios en la Andalucía de la Ilustración, Cádiz, Diputación Provincial, 1991, 2 v.

García-Baquero González, Antonio: La carrera de Indias: suma de la Contratación y océano de negocios, Sevilla, Algaida, Expo'92, 1992.

García-Baquero González, Antonio: «Las remesas de metales preciosos americanos en el siglo XVIII: una aritmética controvertida», Hispania, 56-192, CSIC, 1996, 203-266. 
Gelman, Jorge: De mercachifle a gran comerciante. Los caminos del ascenso en el Río de la Plata colonial, Huelva, Universidad Internacional de Andalucía, 1996.

Haring, Clarence: Comercio y navegación entre España y las Indias, México, FCE, 1939.

Heredia Herrera, Antonia: Sevilla y los hombres del Comercio (1700-1800), Sevilla, Editoriales Andaluzas Unidas, 1989.

Herrero Gil, María Dolores: El mundo de los negocios de Indias. Las familias Álvarez Campana y Llano San Ginés en el Cádiz del siglo XVIII, Madrid, CSIC, Universidad de Sevilla y Diputación de Sevilla, 2013.

Jumar, Fernando: «Comerciantes en Río de la Plata pre-virreinal. El caso Domingo de Basavilbaso», Anuario del Instituto de Historia Argentina, 11, La Plata, 2011, 205-240.

Laviana Cuetos, María Luisa: «La organización de la Carrera de Indias, o la obsesión del monopolio», El comercio marítimo ultramarino. Cuadernos Monográficos del Instituto de Historia Naval, 52, Madrid, 2006, 19-35.

Lohmann Villena, Guillermo: «Los corsos: una hornada monopolista en el Perú en el siglo XVI», Anuario de Estudios Americanos, 51-1, Sevilla, 1994, 15-45.

Malamud, Carlos: «El comercio de neutrales en el Río de la Plata, 1805-1806», Cuadernos de Historia Regional, II-4, Luján, 1985, 17-41.

Martínez Shaw, Carlos: Cataluña en la carrera de Indias, Barcelona, Crítica, 1981.

Michavila Díaz, Alicia: El lenguaje del vestido, Castellón, Universitat Jaume I, 2007.

Miller, Joseph C. (ed.): The Princeton Companion to Atlantic History, Princeton, Princeton University Press, 2015.

Molas Ribalta, Pedro: La burguesía mercantil en la España del Antiguo Régimen, Salamanca, Cátedra, 1985.

Morineau, Michel: Incroyables gazettes et fabuleux métaux. Les retours des trésors américains d'aprés les gazettes hollandaises (XVI-XVII siécles), Paris/London, Éditions de la Maison des Sciences de l'Homme, Cambridge University Press, 1985.

Moutoukias, Zacarías: «Redes personales y autoridad colonial. Los comerciantes de Buenos Aires en el siglo XVIII», Annales. Histoire, Sciences Sociales, 4-5, Paris, 1992, 889-915.

Poensgen, Ruprecht: Die Familie Anchorena 1750-1875. Handel und Viehwirtschaft am Rio de la Plata zwischen Vizekönigreich und Republik, Köln, Böhlau, 1998.

Schlez, Mariano: «Diego de Agüero y los fundamentos económicos de la clase dominante en el Río de la Plata tardo colonial (1770-1810)», en Serrano, José A. y Jáuregui, Luis (eds.), La Corona en llamas. Conflictos económicos y sociales en la independencia iberoamericana, Castellón, Universitat Jaume I, 2010, 27-60. 
Schlez, Mariano: «Enemigos declarados de nuestro sistema. La acción política contrarrevolucionaria de Diego de Agüero y Miguel Fernández Agüero (1770-1816)», Anuario del Instituto de Historia Argentina, 11, La Plata, 2011, 257-295.

Schlez, Mariano: «Antes del fin. Los comerciantes monopolistas frente a la crisis y la revolución (Montevideo, 1789-1820)», Tiempos de América, 19, Castellón, 2012, 17-35.

Schlez, Mariano: «Comercio y sociedad en el Virreinato del Río de la Plata (17701820)», en Cava Mesa, Begoña (coord.), América en la Memoria: Conmemoraciones y Reencuentros, Bilbao, Asociación Española de Americanistas y Universidad de Deusto, 2013a, II, 427-446.

Schlez, Mariano: «Los comerciantes de Buenos Aires frente al comercio de neutrales (1796-1806)», Temas Americanistas, 30, Sevilla, 2013b, 63-86.

Schlez, Mariano: «Entre Dios y la Revolución. El clero rioplatense frente a la Revolución de Mayo de 1810. Los casos de Julián Segundo de Agüero y Juan Manuel Fernández de Agüero», Naveg@mérica, 12 (en línea), Murcia, 2014, http://revistas.um.es/navegamerica [consultado 2 de agosto de 2014].

Silva, Hernán Asdrúbal: El comercio entre España y el Río de la Plata (17781810), Madrid, Banco de España, 1993.

Silva, Hernán Asdrúbal: «La guerra de 1796 y la apertura rioplatense al tráfico marítimo internacional», en Lobato, Isabel y Oliva Melgar, José María, El sistema comercial español en la economía mundial (siglos XVII-XVIII). Homenaje a Jesús Aguado de los Reyes, Huelva, Universidad de Huelva, 2013, 303-323.

Socolow, Susan: Los mercaderes del Buenos Aires virreinal: familia y comercio, Buenos Aires, De la Flor, 1991.

Supervielle Hernández, Manuel G.: La burguesía gaditana en la crisis del Antiguo Régimen (1808-1820), Cádiz, Universidad de Cádiz, 2004.

Torres Sánchez, Rafael (ed.): Capitalismo mercantil en la España del siglo XVIII, Pamplona, EUNSA, 2000.

Vila Vilar, Enriqueta: «Los Corzos: un "clan" en la colonización de América. Apuntes para su historia», Anuario de Estudios Americanos, 42, Sevilla, 1985, 1-42.

Vilar, Pierre: La Catalogne dans l'Èspagne Moderne. Recherches sur les fondements economiques des structures nacionales, Paris, SEVPEN, 1962.

Wallerstein, Immanuel: El moderno sistema mundial I, México, Siglo XXI, 1979.

Werner, Michael y Zimmermann, Bénédicte: «Beyond Comparison: Histoire Croisée and the Challenge of Reflexivity», History and Theory, 45-1, Wiley, 2006, 30-50. 